\title{
ESTUDIO GEOARQUEOLÓGICO INICIAL DE LA FORMACIÓN DE ALEROS Y SUS RELLENOS EN LA LOCALIDAD PUNTA PÓRFIDO(RÍO NEGRO, ARGENTINA)
}

\author{
INITIAL GEOARCHEAOLOGICAL STUDY OF THE FORMATION OF \\ ROCKSHELTERS AND THEIR FILLINGS IN PUNTA PORFIDO (RÍO NEGRO, \\ ARGENTINA)
}

Cristian M. Favier Dubois ${ }^{1,2}$, Dalila Herrera Villegas ${ }^{3}$, Ana P. Alcaraz ${ }^{2}$, Marcelo Cardillo $^{3}$ y Paula Vitale ${ }^{2}$

\begin{abstract}
En la costa semiárida del norte de Patagonia (Golfo San Matías, Río Negro) se observan serranías constituidas por riolitas que ilustran diferentes etapas en la evolución de cavidades rocosas. Un estudio comparativo sobre las mismas en el área de Punta Pórfido permitió comenzar a evaluar los procesos de formación de aleros y sus rellenos sedimentarios. La morfología de las cavidades en este sector resulta del patrón romboidal de diaclasas que presenta la roca de caja y de procesos de meteorización, principalmente el desarrollo de tafoni. Los rellenos se hallan constituidos principalmente por derrubios tamaño grava y bloque derivados de la meteorización de la riolita, a lo que se suma el aporte de sedimentos finos de origen eólico y de sales marinas que han colaborado en la preservación de restos orgánicos inusuales. En la principal cavidad relevada, el Alero 2, se realizaron dos excavaciones y cuatro dataciones radiocarbónicas que proporcionaron edades sobre carbón entre ca. 2200 y 7500 años cal. AP. En esta contribución se presentan los resultados iniciales del estudio geoarqueológico de estas cavidades en la zona costera de Punta Pórfido, orientado a comprender su desarrollo y algunas propiedades del registro arqueológico y tafonómico que contienen sus rellenos.
\end{abstract}

Palabras claves: arqueología, formación de oquedades rocosas y aleros, costa norpatagónica argentina.

\begin{abstract}
Along the semi-arid coast of northern Patagonia (Golfo San Matías, Río Negro) mountain ranges composed of rhyolites illustrate different stages in the evolution of rock cavities. A comparative study carried out in the Punta Pórfido area allows us to evaluate rockshelter formation processes and their sedimentary fillings. Cavity morphology in this sector results from the romboidal pattern of joints in the volcanic rock and weathering processes, mainly the development of tafoni. The fillings are made up of gravel and blocks derived from the weathering of the rhyolite, with the contribution of fine sediments originating from wind and marine salts that have collaborated in the preservation of unusual organic remains. At the main cavity surveyed, Alero 2, two excavations were carried out and four radiocarbon dating samples determined the ages on charcoal to be between ca. 2200 and 7500 years cal. AP. In this contribution, we present the initial results of the geoarchaeological study of these cavities in the coastal area of Punta Pórfido to understand their development and some properties of the archaeological and taphonomic record contained in their fillings. Key words: Archaeology, cavities and rockshelter formation, Argentine northern Patagonian coast.
\end{abstract}

El estudio de la localidad Punta Pórfido forma parte de proyectos de investigación regionales orientados al estudio del uso del espacio y los recursos costeros, así como de las cronologías de ocupación humana en los litorales norte y oeste del Golfo San Matías, Río Negro, Argentina (Figura 1). Estos estudios han tenido un fuerte énfasis en aspectos geoarqueológicos y paleoambientales que dan cuenta de algunas propiedades espaciales y temporales que posee el registro arqueológico a escala regional, como su distribución, composición, resolución temporal y potencial cronológico (Favier Dubois 2019; Favier Dubois y Borella 2011). El desarrollo de un programa de dataciones radiocarbónicas, así como de estudios

1 CONICET - Consejo Nacional de Investigaciones Científicas y Técnicas, Buenos Aires, Argentina.

2 INCUAPA - Facultad de Ciencias Sociales, UNCPBA, Olavarría, Argentina cfavier3@gmail.com; dalila.1083@gmail.com; aalcaraz@soc.unicen.edu.ar; ing.paulavitale@gmail.com

3 IMHICIHU - Instituto Multidisciplinario de Historia y Ciencias Humanas, Buenos Aires, Argentina. marcelo.cardillo@gmail.com 
arqueológicos, geoarqueológicos, paleoambientales y de paleodietas humanas permitieron detectar tendencias temporales en el uso del espacio y los recursos costeros a partir del Holoceno Medio (Favier Dubois y Scartascini 2012; Favier Dubois et al. 2009). Asimismo, se han detectado sesgos en cuanto a la preservación de sitios en contextos eólicos y coluviales, vinculados con la evolución geomorfológica de este litoral en función de los cambios en el nivel del mar (Favier Dubois 2013, 2019).

La costa oeste del golfo San Matías, en particular su tramo sur, ha sido estudiado en la última etapa de las investigaciones (Borella et al. 2015). Este es el único sector del golfo que posee serranías y afloramientos de rocas volcánicas y metamórficas capaces de generar reparos rocosos, tal como se observa en Punta Pórfido.
Allí se desarrollan oquedades en diferentes estadios de evolución que permiten un estudio comparativo acerca de la génesis y las etapas de desarrollo de estas pequeñas geoformas de particular interés arqueológico.

Para que una cavidad se desarrolle deben concurrir una serie de factores que faciliten la génesis de este rasgo en un afloramiento rocoso. En primer lugar, deben combinarse agentes externos e internos para que actúen los procesos de meteorización y erosión sobre la roca iniciando su desagregación y descomposición diferencial. Varios factores controlan este proceso degradativo, resultando los principales: la litología y estructura de la roca (tipo de roca, mineralogía, textura, fracturas), las condiciones climático-ambientales (precipitación, temperatura, vientos, insolación), la biota (principalmente la acción de la vegetación),

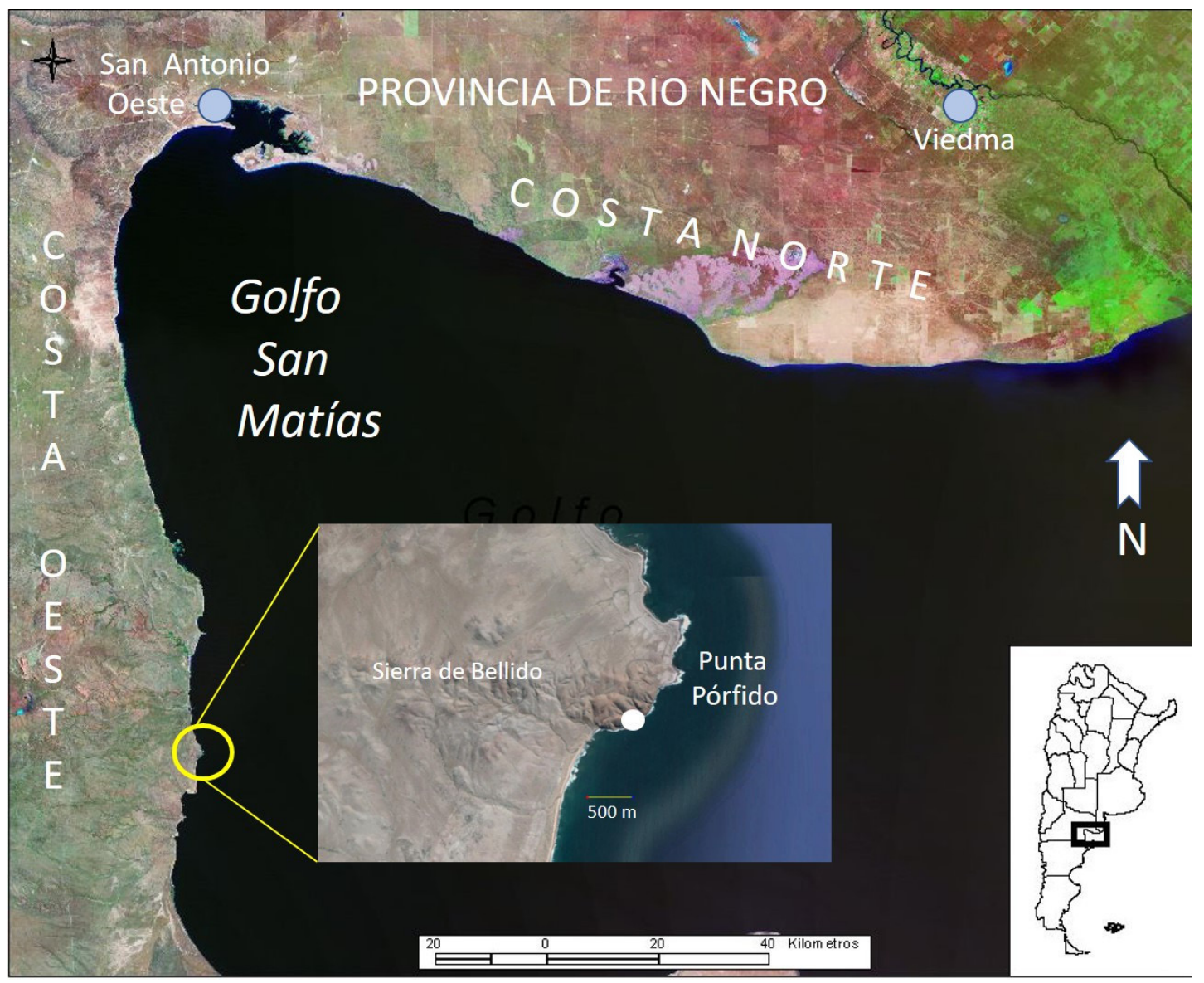

Figura 1. Mapa del área de estudio en la costa de la Provincia de Río Negro. Se destacan la Sierra de Bellido y la Punta Pórfido donde se ubica el Alero 2 (círculo blanco).

Map of the study area along the Río Negro Province coastline, showing Sierra de Bellido and Punta Pórfido, where the Alero 2 site (white dot) is located. 
el marco tectónico (actividad sísmica) y el tiempo (Farrand 1985, 2001; Straus 1990; Waters 1992). Estos factores inician y van modelando el crecimiento de una depresión u oquedad que en determinada etapa de su desarrollo puede llegar a formar un refugio o reparo útil para elementos de la fauna y/o para los seres humanos. Paralelamente, la paulatina desintegración de la roca genera clastos que pueden ser removidos por la erosión o permanecer en la base de la cavidad como un incipiente relleno. Esta oquedad funciona como trampa sedimentaria dado que no solo contendrá los clastos derivados de la roca de caja sino también aquellos aportes sedimentarios clásticos (partículas) y químicos (p.ej., sales, óxidos) procedentes del viento, la gravedad y/o del agua que escurre entre las rocas. A este relleno se suman los materiales clásticos, químicos y biológicos que puedan generar la fauna y los seres humanos a partir del uso del reparo, generándose una suma de aportes autóctonos y alóctonos que van a constituir la estratigrafía del sitio y reflejarán, al menos en parte, su historia de formación y ocupación (Farrand 2001; Goldberg y Sherwood 2006; Straus 1990; Waters 1992). Finalmente, un alero puede erosionarse y perder su relleno, colmatarse o eventualmente colapsar y quedar oculto.

Esta historia de formación, ocupación y desaparición de aleros varía en cada contexto geológico y climático, pero resulta clave para comprender el uso humano de estos espacios en el pasado, su potencial cronología, sus posibles sesgos y el entorno paleoecológico donde tales geoformas se localizan. En este marco, el objetivo de esta contribución es avanzar en el conocimiento del desarrollo de estas cavidades en la localidad de Punta Pórfido a fin de evaluar los procesos de formación, preservación y cronología del registro cultural y natural (tafonómico) en un reparo seleccionado para excavar, el Alero 2.

\section{Área de Estudio}

El Golfo San Matías se ubica en la costa atlántica norte de Patagonia (Provincia de Río Negro, Argentina) (Figura 1). La región posee un clima semiárido, con una temperatura media de $15^{\circ} \mathrm{C}$, precipitaciones menores a los $300 \mathrm{~mm}$ anuales y vegetación arbustiva. Fitogeográficamente corresponde a la provincia del Monte, donde predominan las jarillas (Larrea spp.) (Cabrera y Willink 1980). Las escasas lluvias suelen darse en forma de lloviznas, pero a veces adquieren carácter torrencial, dando lugar a procesos erosivos intensos, principalmente en los meses de marzo, mayo, julio y diciembre (De Alba 1964). Los inviernos son fríos con heladas comunes y temperaturas de $-10^{\circ}$ y $-15^{\circ}$ C. Los suelos son esqueléticos (Entisoles), desarrollados sobre sustratos de arenas y gravas que brindan sustento a la vegetación xerófila arbustiva de bajo porte que predomina. Los afloramientos rocosos suelen estar cubiertos por líquenes foliosos y crustosos, en particular en los frentes que miran hacia el sur, algo más húmedos al recibir menos insolación. La radiación solar es intensa debido a la escasa cobertura nubosa. Las mareas tienen un régimen semidiurno y una amplitud macromareal, con valores medios de unos $6 \mathrm{~m}$ y máximos de hasta unos $9 \mathrm{~m}$ registrados en el principal entrante costero del golfo San Matías, la bahía de San Antonio (Servicio de Hidrografía Naval 2020, Argentina, http://www. hidro.gov.ar/). Los vientos predominantes soplan del cuadrante oeste (NO, O y SO) y son más fuertes entre septiembre y enero (Crisoliti y Pahissa Campá 1973). La sismicidad en la región es muy reducida de acuerdo con el mapa de zonificación sísmica del INPRES (Instituto Nacional de Prevención Sísmica http://contenidos.inpres.gov.ar/publicaciones).

La localidad Punta Pórfido se ubica en la denominada Sierra de Bellido (Figura 1) que se extiende de $\mathrm{O}$ a $\mathrm{E}$ por unos $4 \mathrm{~km}$ hasta alcanzar el litoral marino, donde genera elevados acantilados rocosos $(5$ a $15 \mathrm{~m})$, rodeados de playas de arena y gravas. El oleaje rompe con fuerza contra estos acantilados, en particular durante las pleamares, aportando microgotas salinas a la bruma que afecta los afloramientos rocosos del sector.

La fauna nativa registrada en el área comprende diversas especies de aves marinas, rapaces (Falconiformes y Strigiformes), corredoras (Rheidae) y paseriformes; así como mamíferos carnívoros (zorro gris, puma), roedores (ctenómidos, cricétidos), marsupiales (marmosinos), armadillos (peludo, piche) y ungulados (guanaco). El área se halla afectada en la actualidad por el impacto de la ganadería ovina.

\section{Marco Geológico}

Las serranías bajas que se observan en el tramo sur de la costa oeste del golfo San Matías corresponden al borde oriental del Macizo Norpatagónico y se hallan compuestas por rocas predominantemente volcánicas (lavas, diques y depósitos piroclásticos) de edad Jurásica (Busteros et al. 1998; Gelós et al. 
1990). La Sierra de Bellido forma parte de estas serranías orientales, poseyendo alturas que van de unos 100 a $80 \mathrm{~m}$ y aún menores hacia el $\mathrm{E}$ al acercarse a la costa donde presenta una escarpa elevada que constituye la Punta Pórfido (De Alba 1964). Las rocas que la componen son principalmente riolitas y tobas riolíticas (Gelós et al. 1990) pertenecientes al Complejo volcánico Marifil (Cortés 1981). Estas rocas presentan abundantes diaclasas siendo las principales aquellas de rumbo aproximado N-S y E-O (De Alba 1964), orientaciones que generan un patrón cuadrangular romboidal.

Las riolitas conforman el cuerpo principal de este afloramiento. Poseen tonos rosados, amarillentos y grisáceos, son compactas y de textura porfírica con fenocristales de cuarzo corroído y, subordinadamente, ortosa y sanidina con alteración arcillosa y escasa plagioclasa fuertemente alterada (De Alba 1964; Gelós et al. 1990:399). En estas riolitas se observa la formación de oquedades de diversas dimensiones producto de la meteorización y erosión de las mismas. En relación con estos procesos se destaca el desarrollo de cavidades denominadas genéricamente tafoni (Groom et al. 2015).

\section{Metodología}

Se realizó una recopilación bibliográfica de los antecedentes ambientales, geológicos y geomorfológicos del sector de Punta Pórfido (Busteros et al. 1998; De Alba 1964; Gelós et al. 1990; Olivier 1973), así como un análisis de las imágenes satelitales disponibles en Google Earth (2019) y fotografías de drone (DJI Phantom 3 Standard). Asimismo, se tuvo en cuenta la información resultante de las investigaciones arqueológicas previas en el sector (Borella et al. 2015).

Para este estudio se realizaron prospecciones en un área de unos $800 \mathrm{~m}$ x $500 \mathrm{~m}$ en la que se relevaron decenas de oquedades rocosas en distintas etapas de formación. Paralelamente se tomaron muestras de algunos de sus rellenos para evaluar sus características granulométricas. Asimismo, se efectuaron algunas observaciones actualísticas de carácter tafonómico con relación al potencial de preservación de los restos óseos en el área. Finalmente, se seleccionó para un estudio más detallado el alero que presentó mayor profundidad de relleno (estimada con barreno) y un tamaño apto para la ocupación humana, denominado Alero 2. Las excavaciones en el Alero 2 se desarrollaron entre marzo y abril de 2016 (cuadrícula 1) y en octubre de 2017 (cuadrícula 2). En ambas cuadrículas se llegó a una profundidad aproximada de un metro, en la que se alcanzó la roca de caja (riolita). La inclinación de la superficie del terreno y de las capas que buzaban en estratigrafía se midió con clinómetro. La excavación procedió por niveles de $10 \mathrm{~cm}$ y el sedimento se pasó por zaranda de $1 \mathrm{~mm}$ de malla. Se recuperaron en estratigrafía artefactos líticos, restos faunísticos y carbones. A partir de estos últimos se obtuvieron cuatro dataciones por ${ }^{14} \mathrm{C}$. Tres de ellas fueron realizadas por el método convencional en el Laboratorio de Radiocarbono de La Plata (ex Latyr, Argentina), y la cuarta por AMS en los laboratorios de DirectAMS en Seattle, Washington (USA). Las edades fueron calibradas con el programa CALIB 7.1, curva SHcal13 a $1 \sigma$.

La única fauna de vertebrados recuperada fueron restos de microvertebrados (roedores, marsupiales y aves pequeñas). Sobre estos se llevaron a cabo determinaciones anatómicas y taxonómicas y medidas de cuantificación (NISP, MNI, MNE, Ri [abundancia relativa]; Andrews 1990; Lyman 2008) en particular en la cuadrícula 2 donde resultaron más abundantes. Asimismo, para evaluar los potenciales procesos y/o agentes causales de la presencia de estos restos en el depósito se llevó a cabo el análisis de variables tafonómicas tales como: meteorización, corrosión gástrica, abrasión, marcas de raíces y depositaciones químicas (Andrews 1990; Fernández-Jalvo y Andrews 2016). Por otro lado, se recuperaron muestras de sedimento a intervalos regulares en la estratigrafía sobre las que se efectuaron análisis granulométricos mediante tamizado (tamices de $2 \mathrm{~mm}, 1 \mathrm{~mm}, 0,42$ $\mathrm{mm}$ y $0,075 \mathrm{~mm}$ de apertura) y utilizando un equipo de difractometría láser (Malvern Mastersizer 2000, Facultad de Ingeniería, Universidad Nacional de la Patagonia San Juan Bosco, Esquel). Se realizaron además análisis geoquímicos (Laboratorio LAPREI, Facultad de Ciencias Sociales, UNICEN, Olavarría) orientados a estimar el $\mathrm{pH}$ en pasta acuosa (1:2,5 con sedimento seco) así como la cantidad y tipos de sales solubles en el sedimento. Respecto a estas últimas, se identificaron los iones mayoritarios en una disolución acuosa 1:10 filtrada utilizando métodos estandarizados. La determinación de cloruros se realizó mediante valoración con nitrato de plata (SM4500-Cl B), la concentración de bicarbonatos se determinó mediante valoración con solución ácida (SM2320-B). La medición de calcio y magnesio se 
realizó por valoración complejo-métrica (SM2340 C). El contenido de nitratos, nitritos y amonio se determinó mediante técnicas colorimétricas $\left(\mathrm{SM} 4500-\mathrm{NO}_{3} \mathrm{~B}\right.$; $\mathrm{SM} 4500-\mathrm{NO}_{2} \mathrm{~B}$ y SN4500-NH $\mathrm{N}_{3} \mathrm{C}$ ). El contenido de sodio y potasio se determinó por fotometría de llama. Los sulfatos solubles fueron analizados por gravimetría llevándolos a sulfato de bario (SM 4500-SO42-C).

\section{Resultados}

\section{La formación de oquedades y sus rellenos en Punta Pórfido}

\section{Factores de control en la formación de oquedades y aleros}

Entre los factores de control litológico-estructural que intervienen en la génesis y evolución de oquedades y aleros de Punta Pórfido hemos observado dos que parecen ser los principales: (1) la presencia de un sistema de diaclasas (fracturas orientadas que se cortan en ángulos agudos de unos 60 grados) en gran parte de las riolitas aflorantes, y (2) el desarrollo de procesos de meteorización que generan tafoni en aquellas superficies de roca poco o no dominadas por diaclasas. Nos referiremos por separado a uno y a otro factor, aunque puedan combinarse para dar cuenta de la morfología final de algunas de las cavidades observadas. En ambos casos los principales responsables de la desagregación y descomposición de la roca son los procesos de meteorización físicoquímica y en forma subalterna la erosión que remueve los productos de la meteorización.

En el caso de las rocas diaclasadas, la presencia de estas fracturas aumenta la fragilidad y permeabilidad de la roca, facilitando la infiltración. En los planos de fractura se produce la alteración química de los silicatos de la riolita por acción del agua, proceso que incluye la hidrólisis de feldespatos potásicos y plagioclasas, que se transforman en arcillas (Scasso y Limarino 1997). Este proceso de meteorización en las grietas resta estabilidad y resistencia a la roca. Por otro lado, la meteorización física también actúa en los planos de fractura a través del crecimiento de pequeños cristales de sales, vinculado al aporte de la bruma marina en el sector, a partir de ciclos de humedecimiento-desecación (haloclastía). Dependiendo de la ubicación del frente rocoso respecto del mar y del viento, el aporte de humedad y sales puede tener una mayor o menor influencia en el proceso de meteorización. Se ha observado que al alejarse de la costa la cantidad de oquedades en las superficies rocosas disminuye. El crecimiento de cristales de hielo en función de la humedad matinal (rocío) y/o aquella aportada por la bruma es otro factor a considerar, propiciando procesos de crioclastismo (ciclos diurnos de congelamiento-descongelamiento invernales). A la descomposición química y la meteorización mecánica que operan en las diaclasas, pueden sumarse otros factores físicos como la acción de las raíces de arbustos y la esporádica actividad sísmica, lo que genera, en suma, la desagregación de la roca a favor de estos planos de fracturas, cuya intersección da origen a cavidades de morfología romboidal, evidenciando un control estructural (Figura 2). Este control puede ser predominante en la morfología de aleros y cuevas desarrollados en algunas otras regiones, como ocurre en el sistema serrano de Tandilia, en la provincia de Buenos Aires (Martínez 2007), donde muchas cavidades poseen formas rectangulares.

Por otra parte, los tafoni (en singular tafone) son cavidades semiesféricas de variados tamaños que se desarrollan en distintas litologías y se consideran principalmente resultado de procesos de meteorización y secundariamente erosión, aunque los mecanismos involucrados en cada caso son variables y aún objeto de debate (Groom et al. 2015). Se distribuyen en forma aparentemente azarosa sobre la superficie rocosa, lo que podría responder a puntos de debilidad mineralógica o estructural. Turkington y Phillips (2004) señalan que variaciones iniciales muy localizadas, que pueden ser muy pequeñas, en la resistencia a la intemperie, como pueden ser las características microtopográficas, los impactos bióticos o las fracturas, tienden a amplificarse con el tiempo en un proceso divergente respecto al resto del frente rocoso. Una vez iniciado el proceso, el microambiente que se genera dentro de estas cavidades puede amortiguar los cambios de temperatura y generar humedades relativas más altas acelerando los procesos de meteorización química (Turkington 2004). Si bien se considera a los tafoni como estructuras poligenéticas en las que intervienen factores concurrentes, el papel del agua y de las sales resultaría importante para su desarrollo (Huinink et al. 2004; Schnepfleitner et al. 2015; Turkington 2004). En Punta Pórfido se observa que estas cavidades se ven ampliadas por la exfoliación progresiva de las superficies interiores y su desprendimiento en forma de láminas delgadas y gránulos angulosos de variados tamaños (Figura 3). Una explicación 


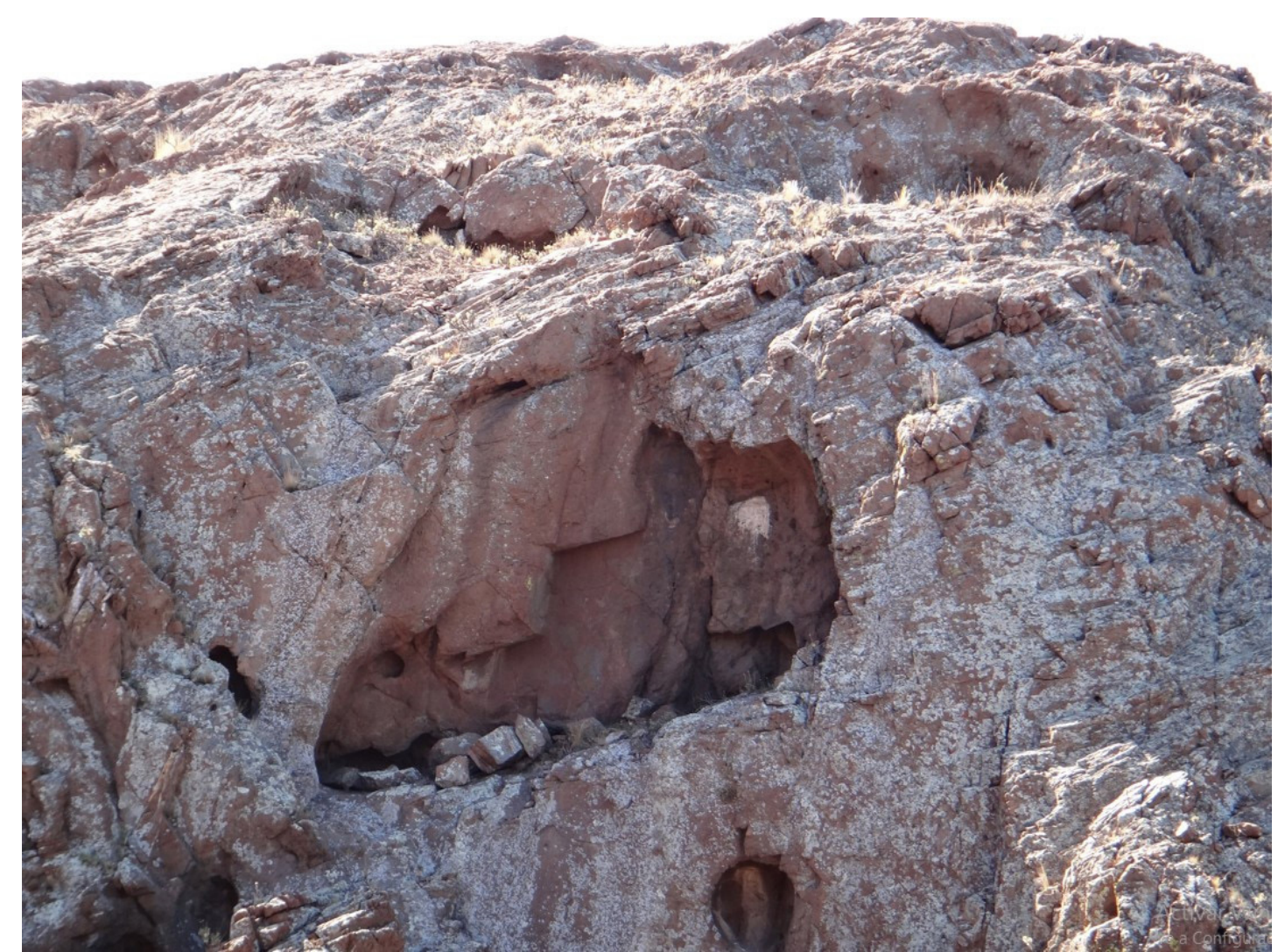

Figura 2. Control estructural de las diaclasas sobre la morfología de algunas cavidades. Nótense también, en la base de la oquedad, los bloques cuadrangulares desprendidos.

Structural control of the joints on the morphology of some cavities. Also note some detached square blocks at the base of the cavity.

que puede invocarse para este proceso de exfoliación es la expansión diferencial de aquellos minerales que se alteran a arcillas durante la meteorización química (p.ej., feldespatos potásicos y plagioclasas) generando una tensión que separa láminas (Skinner y Porter 2000). A esta desagregación puede colaborar también en este contexto la haloclastía (Huinink et al. 2004; Schnepfleitner et al. 2015). Otro mecanismo que podría sumarse es la expansión térmica diferencial de los minerales de la roca durante los ciclos diurnos marcados de calentamiento y enfriamiento, que podrían colaborar con la fragmentación (Goudie 2004:567). La gravedad, el viento y el agua van removiendo el material flojo o suelto de las paredes y base de las cavidades, que se continúan ampliando a medida que evoluciona el proceso. Su forma tiende a ser esferoidal y pueden coalescer unas con otras al aumentar su tamaño generando cavidades mayores.

Así como los agentes geológicos tienen una participación importante en la meteorización de las rocas, también poseen un papel los agentes biológicos (p.ej., líquenes, bacterias, algas y hongos), dado que modifican las superficies rocosas (Villar et al. 1983). En Punta Pórfido, los líquenes (foliosos y crustosos) tapizan muchas paredes exteriores a las cavidades, en particular en los frentes rocosos que miran hacia el sur (Figura 2). Estos organismos provocan daños por acción mecánica (ricines) y química (ácidos liquénicos) en los sectores donde se fijan (Alquiza et al. 2015; Rosato 2010). Contribuyen a la descomposición de las riolitas y constituyen un posible agente de inicio de cavidades en Punta Pórfido.

\section{El relleno de las cavidades}

En los rellenos de las cavidades rocosas de Punta Pórfido es posible distinguir entre aquellos de origen geológico (1), de origen biológico (2) y de origen antrópico (3).

(1) Entre los rellenos de origen geológico podemos distinguir los autóctonos y los alóctonos. Entre los primeros se destaca el aporte clástico por gravedad 


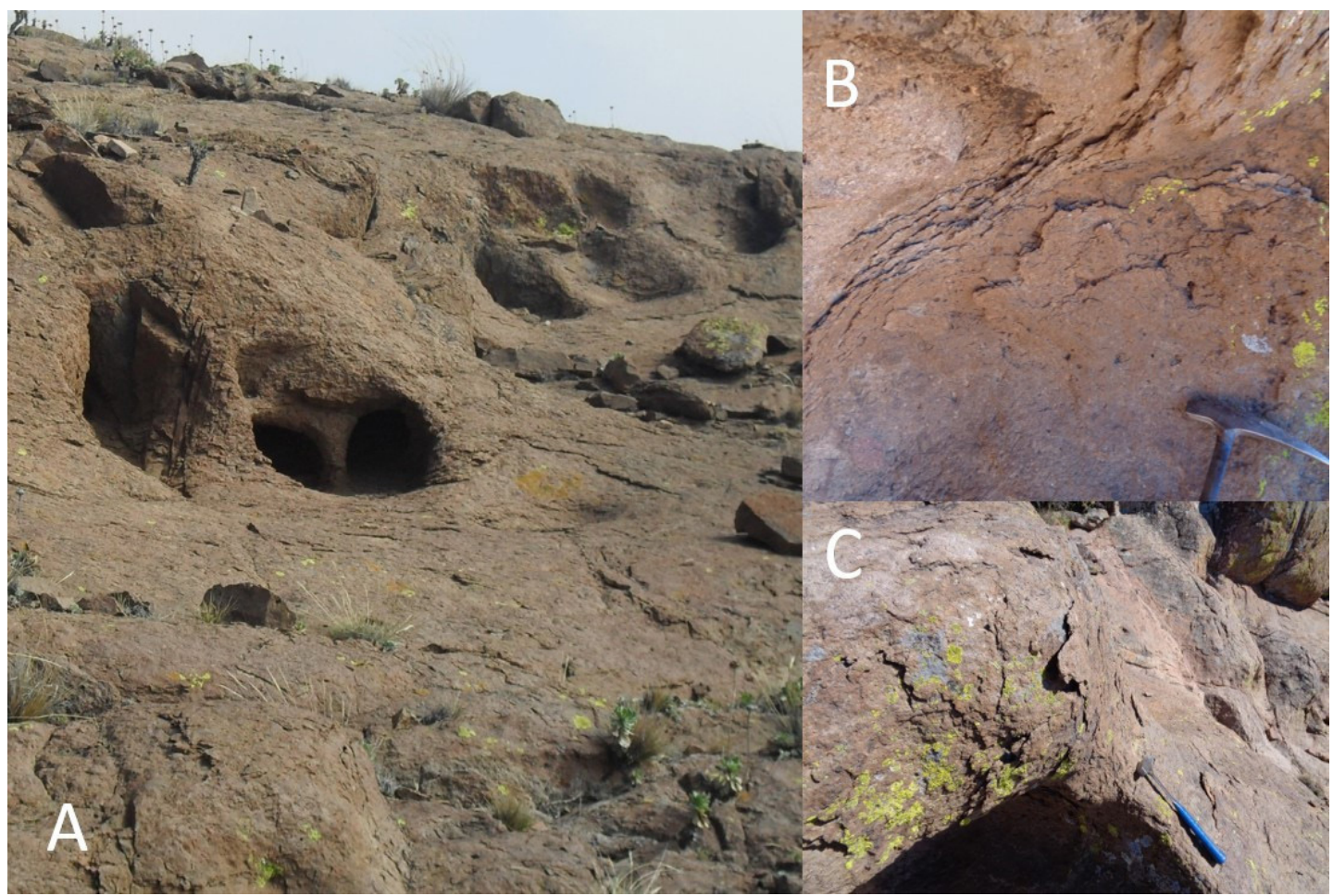

Figura 3. Desarrollo de tafoni en los afloramientos riolíticos de Punta Pórfido, con detalle de los procesos de exfoliación.

Development of tafoni in the rhyolitic outcrops of Punta Pórfido, with details of the exfoliation processes.

desde el techo y las paredes a partir de exfoliaciones laminares y el desprendimiento de derrubio anguloso derivado de la meteorización de la roca de caja (Figura 3), a lo que se suma la caída de bloques derivada de fracturas irregulares y diaclasas (Figura 2). El aporte autóctono de origen químico que se genera por procesos de disolución y que resulta muy destacado en rocas carbonáticas (ambientes kársticos), no parece importante en este caso por el tipo de roca de caja.

Respecto al material geológico de origen alóctono, el viento resultaría el principal agente de aporte. Es intenso y constante en la región, no obstante, su contribución se concentra en las oquedades que poseen una ubicación propicia para que el flujo aéreo cargado de partículas pierda energía y las deposite. La vegetación que se desarrolla en el frente y cercanía de las oquedades es también importante en este proceso de sedimentación, ya que atrapa y retiene las partículas movilizadas por el viento, colaborando en generar una trampa efectiva. Esta vegetación (arbustiva y herbácea) retiene partículas finas a la vez que permite el desarrollo de un horizonte A de suelo, que favorece la permanencia y estabilidad de este depósito sobre los afloramientos rocosos. La contracara de la acción del viento son los procesos de erosión eólica que ocurren cuando las oquedades se encuentran en posiciones que reciben un fuerte flujo directo (a veces encauzado por la topografía), que elimina la posibilidad de acumulación de sedimentos o la fijación de vegetación. Otro material alóctono importante en esta zona es el transportado por la bruma marina en la forma de sales solubles. Estas se observan en la base de algunas oquedades y se concentran en los niveles superiores del Alero 2, en la forma de concreciones y pátinas salinas.

(2) Los aportes de origen biológico al relleno corresponden a los materiales generados por elementos de la fauna que ocupan oquedades y aleros. En los reparos de la zona se han observado numerosas "perchas" (posaderos de aves) correspondientes a los abundantes jotes de cuello negro (Coragyps atratus) presentes en la región. Estas aves carroñeras se resguardan en las cavidades desarrolladas en las rocas y generan acumulaciones de guano en esos lugares, algunas de ellas de decenas de centímetros de espesor. Se debe contemplar el posible aporte de egagrópilas (bolos de regurgitación) y elementos no digeridos por parte de 
estas aves (Ballejo et al. 2012). Otros habitantes de estos reparos rocosos son las rapaces nocturnas (Strigiformes), como la lechuza de los campanarios (Tyto furcata), que ocupan la región. En el Alero 2, tanto en superficie como en estratigrafía se han recuperado egagrópilas que, por su morfología y tamaño, parecen corresponder a las generadas por lechuzas y búhos. Dichos bolos contienen pelo y abundantes restos de fauna, como huesos de roedores de las familias Sigmodontinae, Caviidae y Ctenomyidae, de marsupiales (Didelphidae), de aves de pequeño tamaño (Passeriformes) y cuerpos de insectos, que pueden incorporarse a los rellenos de oquedades y aleros como aporte biológico (Andrews 1990). En este sentido, podemos mencionar que en cernidor se recuperaron varios elementos óseos de micromamíferos muchos de los cuales aún conservaban restos de pelos adheridos y evidencias de corrosión gástrica, lo que indica que proceden de egagrópilas disgregadas. Asimismo, no debemos descartar la posibilidad del aporte directo de huesos de roedores que habitaron el alero a partir de muertes naturales in situ. También se han recuperado plumas (especies no identificadas) en la estratigrafía del Alero 2 como otro probable aporte tafonómico de la fauna aviaria que ocupó estas cavidades.

(3) El aporte antrópico, por su parte, ha sido modesto en el alero excavado. Consiste primariamente en delgadas lentes de carbones y cenizas ( $1 \mathrm{a} 3 \mathrm{~cm}$ de espesor), un instrumento lítico y algunas lascas y microlascas (sobre calcedonia, chert, cuarzo y riolita), fragmentos de valvas (indeterminados), pequeños gasterópodos marinos y un elemento óseo humano (ver más detalles en el sitio Alero 2). En dos oquedades cercanas al Alero 2 se han realizado hallazgos aislados de artefactos líticos en superficie (denticulado y lasca), pero no han sido recuperados otros materiales arqueológicos al momento en los pequeños aleros y oquedades relevados en Punta Pórfido.

\section{Aspectos tafonómicos y condiciones geoquímicas de preservación}

Fuera de los reparos rocosos es muy baja o nula la sedimentación sobre los afloramientos de riolitas. Ello dificulta la preservación de elementos de origen orgánico como restos óseos o valvas de moluscos marinos en estos sectores. Se han observado algunos restos óseos de ovinos y guanaco que se hallan fragmentados y muy deteriorados al permanecer expuestos a la intemperie sobre los afloramientos rocosos. Dentro de las cavidades existen mayores posibilidades para la preservación de estos materiales. Allí las condiciones climáticas se hallan atemperadas, constituyendo un ambiente resguardado de los agentes de meteorización exteriores, en el que existe además la posibilidad de incorporación al relleno. Tal incorporación dependerá en gran medida de la tasa de sedimentación, que resulta de la suma de los aportes autóctono y alóctono en el interior de las cavidades. El primero de estos aportes, dominado por procesos de meteorización, es muy lento, por lo que de actuar como único aporte da lugar a tasas de acumulación muy bajas. Esta tasa se incrementa con el aporte alóctono (eólico en este caso). En los rellenos de las oquedades se han observado condiciones variables respecto al aporte alóctono, dependiendo de la ubicación y orientación del reparo, aunque predomina siempre el material autóctono. En el caso del Alero 2 el aporte eólico forma parte del 24 al 29\% del componente clástico en la matriz. En otro pequeño alero se han registrado porcentajes menores al $10 \%$. Los porcentajes señalados, si bien resultan bajos, colaboran con la sedimentación y las posibilidades de enterramiento. También pueden contribuir a la incorporación de materiales de origen orgánico al sustrato las actividades de los seres humanos (p.ej., pisoteo, limpieza de fogones, acondicionamiento del espacio) y de la fauna que eventualmente ocupa el sitio (p.ej., tránsito de aves, roedores, carnívoros). Una vez enterrados, estos materiales se ven sometidos a nuevas variables de preservación. En este estudio se tuvieron en cuenta dos de ellas, las condiciones de acidez-alcalinidad del sustrato $(\mathrm{pH})$ y las sales presentes. Los análisis efectuados en el Alero 2 proporcionaron valores de $\mathrm{pH}$ entre ligeramente ácidos y levemente alcalinos a lo largo de la secuencia. Ello, sumado a que se trata de depósitos porosos bien drenados (ambiente oxidante), genera condiciones muy adecuadas para la preservación de restos óseos y valvas de moluscos (Retallack 1990). Por otro lado, en la parte superior de la secuencia, particularmente en la cuadrícula 2, abundan las sales solubles. Estas sales han permitido la preservación de elementos particularmente delicados como plumas y egagrópilas (incluyendo pelo) en la estratigrafía del sitio, al inhibir la acción de bacterias y hongos. La baja humedad en la región ha sido otro factor relevante, ya que ha posibilitado que estas sales permanezcan sin ser lavadas de los rellenos, sumando su efecto higroscópico (absorben humedad).

En relación con el análisis tafonómico de los restos óseos recuperados en el Alero 2, estos evidencian, 
en general, un alto grado de preservación. Entre las modificaciones observadas en las superficies óseas, el $13 \%(n=28)$ de los especímenes presentaban tinciones de manganeso que se manifiestan como pequeñas manchas oscuras distribuidas azarosamente; en el $8,7 \%(n=19)$ se observó la presencia de sales solubles presentes como pátinas y/o concreciones blanquecinas sobre los restos. En un 1,8\% $(n=4)$ se identificaron evidencias de meteorización (estadios 1 y 2) y marcas de raíces. Sumado a esto, el 13,9\% $(n=27)$ de los especímenes de roedores analizados (dientes y elementos postcraneales), presentaron algún tipo de corrosión digestiva. Entre estos, el $80 \%$ corresponde a la categoría ligera de corrosión, mientras el 20\% restante a la categoría moderada. Es importante notar que el 57\% de los restos recuperados presentan algún grado de fragmentación. A partir de las características de los bordes de fractura es posible sugerir que en su mayoría serían consecuencia de procesos postdepositacionales como el pisoteo, acción que también pudo favorecer su incorporación al sustrato.

\section{El Sitio Alero 2}

\section{Características del alero y cuadrículas excavadas}

El Alero 2 se halla ubicado en la pared sur de un pequeño cañadón de unos $300 \mathrm{~m}$ de largo con dirección noroeste-sudeste, que desemboca en el mar (Figura 4). Su frente mira al noreste lo que hace que no tenga una exposición directa a los vientos predominantes (cuadrante oeste) y que solo reciba los rayos del sol a partir del mediodía. No obstante, el alero recibe la influencia de la bruma marina que procede del cuadrante este.

En este sector, la riolita de caja presenta abundantes diaclasas y se observan tafoni de diferentes tamaños en variadas posiciones del afloramiento. El propio alero parece haberse originado por la conjunción de al menos dos grandes tafone que han coalescido, pero en cuya formación las diaclasas también han jugado un papel (Figura 5). La altura del alero es de unos 4,50 m desde la línea de goteo hasta la superficie

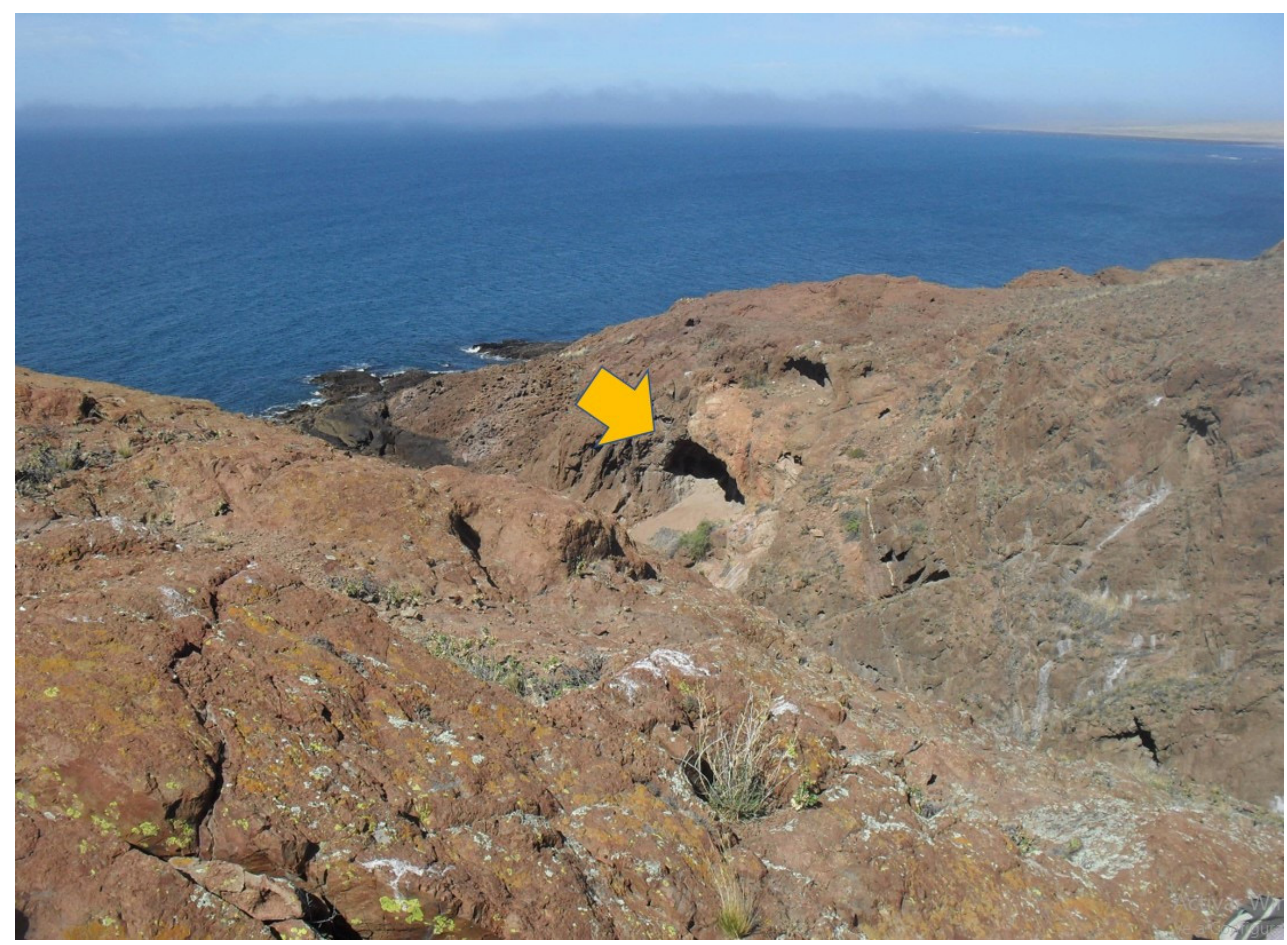

Figura 4. Vista del Alero 2 (flecha) y su contexto geomorfológico.

Alero 2 (arrow) and its geomorphological context. 
actual del relleno. La distancia entre la parte más profunda de este reparo y la línea de goteo es de 4,40 $\mathrm{m}$, mientras que el frente del alero tiene un ancho de $9,50 \mathrm{~m}$ (relación ancho-profundidad de 2,11). Teniendo en cuenta que la profundidad de esta geoforma y la altura del techo son factores que controlan el impacto de las condiciones climáticas en el interior, podemos decir que resulta abierto y estrecho, lo que genera un ambiente escasamente reparado para los seres humanos. Si bien esta observación es actual no parece haber sido muy diferente su condición en el pasado (hasta un metro menos de relleno en una cavidad algo menor), hecho que pudo haber influido en su uso a lo largo del tiempo.

Debido a la morfología de doble oquedad, el alero fue dividido en dos sectores para su excavación, denominados 1 y 2 . Esto permitió evaluar el comportamiento estratigráfico en cada caso y comparar las secuencias representadas. La superficie del alero presenta abundante derrubio anguloso de origen autóctono, en el que predomina el tamaño gravilla (2 a $5 \mathrm{~mm}$ ) y sobre el que se observa el desarrollo de vegetación arbustiva desde la línea de goteo hacia el exterior. No se registró la presencia de guano de oveja en el piso del alero, pero sí la de dos excrementos de zorro. La superficie evidencia una fuerte y continua inclinación en dirección al cañadón, con valores de pendiente medidos entre $24^{\circ}$ y $25^{\circ}$.

La cuadrícula planteada en el sector 1 fue de $100 \mathrm{~cm}$ x $60 \mathrm{~cm}$ y en el sector 2 de $100 \mathrm{~cm}$ x 100 $\mathrm{cm}$. Ambas cuadrículas fueron excavadas por niveles artificiales de $10 \mathrm{~cm}$ respetando la inclinación de la superficie y de las capas naturales. El relleno se observaba ligeramente estratificado en los dos sectores profundizados, destacándose algunas variaciones granulométricas vinculadas con la caída

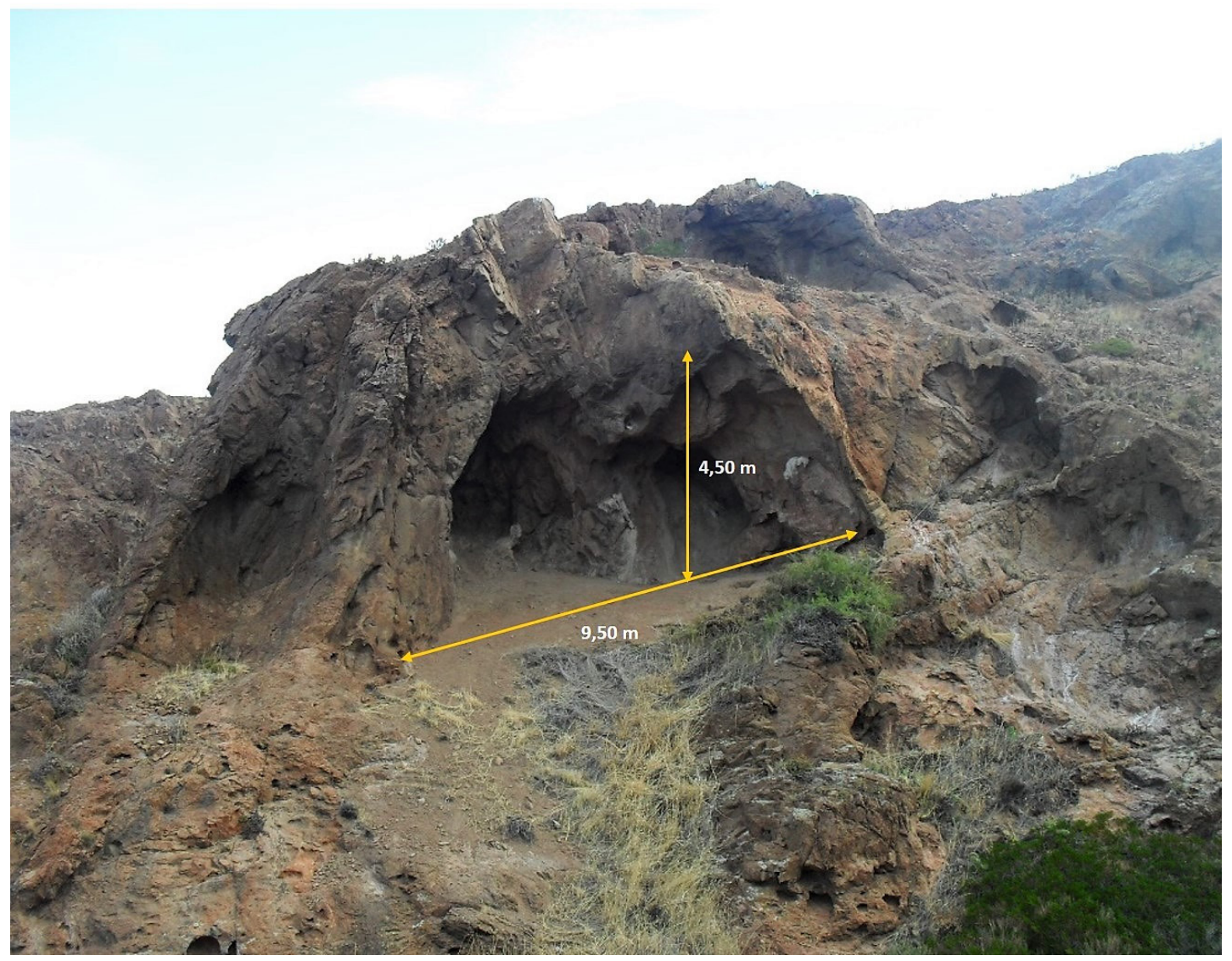

Figura 5. El Alero 2 en vista frontal.

Front view of Alero 2. 
de clastos de mayor tamaño (Figura 6). También se registró la presencia de niveles salinos blanquecinos (concentraciones de sales solubles), especialmente en la parte superior de la cuadrícula 2. En ambos casos se destaca la presencia de delgadas lentes de carbones y cenizas, de hasta $3 \mathrm{~cm}$ de espesor, consideradas de origen antrópico (Figura 6). La excavación alcanzó profundidades de $1 \mathrm{~m}$ en la cuadrícula 1 y de 1,20 $m$ en la cuadrícula 2. A continuación, se reseñan los principales hallazgos en cada una de ellas.

Cuadrícula 1: en esta cuadrícula se excavaron diez niveles de $10 \mathrm{~cm}$ cada uno. Se registraron cuatro delgadas lentes de carbones y cenizas (niveles 2 , 3,4 y 7) y carboncillos muy dispersos en otros niveles. Respecto al material lítico, se recuperaron 25 artefactos (principalmente lascas angulares y microlascas) doce de ellos en superficie (48\%), el resto de los artefactos se recuperó en los niveles 1 y
6. El único instrumento recuperado en capa fue un denticulado confeccionado sobre chert. En cuanto a las materias primas se reconocieron siete tipos, tres de ellas se hallarían inmediatamente disponibles (riolita similar a la roca de caja, cuarzo y una pizarra procedente de un afloramiento cercano) y poseen, en general, de buena a muy buena calidad para la talla $(76 \%)$. La reserva de corteza en el material recuperado es muy escasa y se observa solo en un $8 \%$; tampoco se recobraron núcleos. En el nivel 2 se registraron pequeños fragmentos de valvas marinas indeterminadas (¿Mytilidae?). Se recuperaron además algunas egagrópilas enteras $(n=2)$ o parcialmente disgregadas $(n=3)$ en muy buen estado de preservación (superficie y niveles 1 y 2). En el nivel 3 se registró la presencia de pequeños gasterópodos (Trophon $\mathrm{sp}$.) asociados a carbones y huesos de microvertebrados, pero sin marcas de combustión. También una pluma

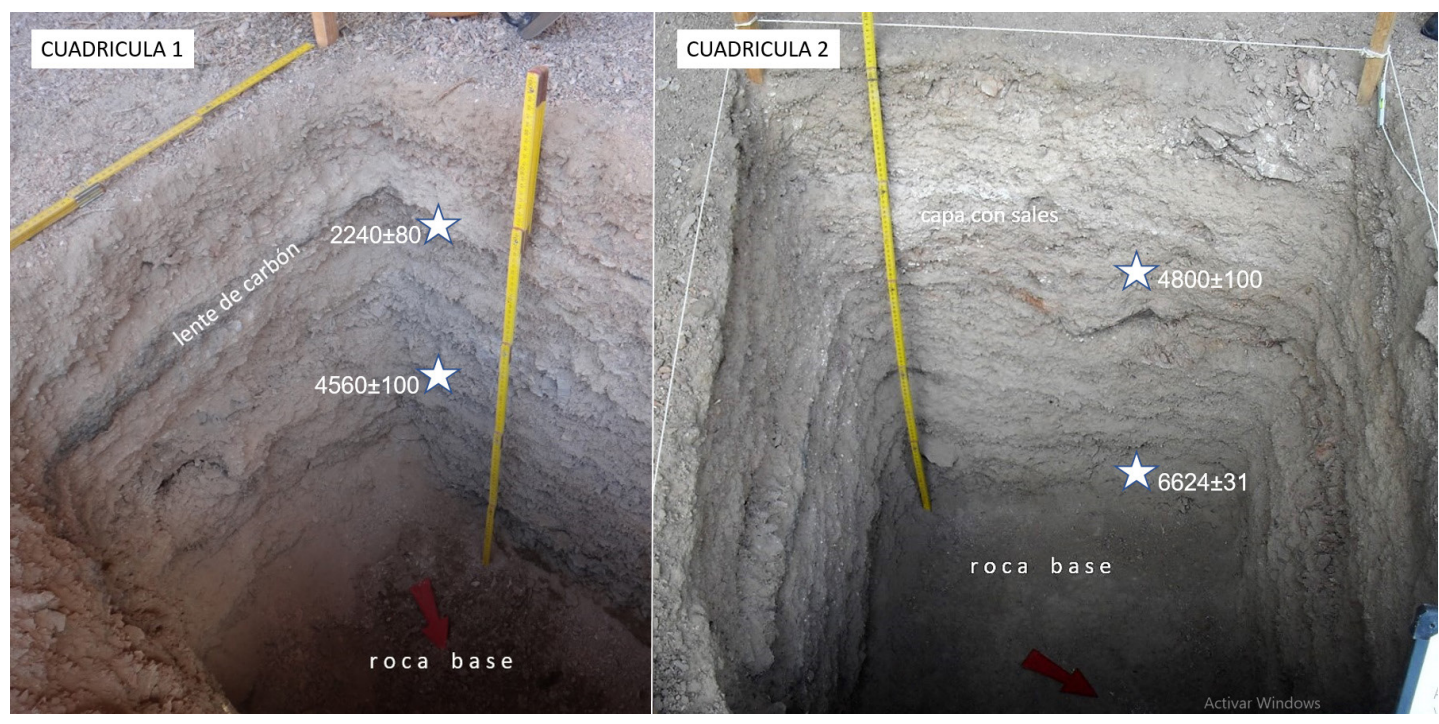

Figura 6. Vista de la estratigrafía en las cuadrículas 1 y 2, se indica la ubicación de las muestras datadas y la edad radiocarbónica obtenida en cada caso.

Stratigraphy in grids 1 and 2; locations of dated samples are indicated as well as the radiocarbon ages obtained.

de ave indeterminada. Los restos óseos son escasos en comparación con los hallados en la cuadrícula 2 y se distribuyen en los primeros cuatro niveles. Se recuperaron 54 especímenes de roedores correspondientes en su mayoría a las familias Cricetidae y Ctenomiydae. A esto se suman dos elementos de alguna especie de marmosino (Didelphidae) y cuatro restos de Passeriformes. En el nivel 5 se registró una posible cueva de roedor. En el nivel 6 se registró una falange ungueal humana. Por debajo del nivel 6 la evidencia cultural (carboncillos) y tafonómica (microvertebrados) se hace escasa y se observa un incremento en la humedad. En el nivel 8 comienza a aflorar la roca base en la pared SO de la cuadrícula, que buza hacia el exterior del alero (NE) y 
presenta evidencias de meteorización in situ. Los niveles basales fueron casi estériles (escasos microcarbones).

Cuadrícula 2: en este caso se excavaron doce niveles de $10 \mathrm{~cm}$ cada uno. Se registraron cuatro delgadas lentes de carbones y cenizas (niveles 3, 4, 8 y 9). En los tres primeros niveles se destacaba la presencia de sales, expresándose en capas de sedimento brechoso concrecionado por las mismas, con desarrollo de cristales, o en pátinas blanquecinas sobre los clastos. En el nivel 1 se halló una pequeña pluma preservada. En los niveles 2 y 4 se recuperaron fragmentos de valvas de moluscos marinos (¿Mytilidae?). Se registró asimismo un fragmento de cáscara de huevo (indeterminada) en el nivel 4. Se recuperaron 196 restos de micromamíferos y 21 fragmentos óseos indeterminados (Tabla 1) distribuidos en casi todos los niveles, aunque la mayor frecuencia se concentró en la sección superior (niveles 1 a 4). Entre los especímenes óseos y dentarios recuperados fue posible identificar la presencia de diversos taxa de roedores sigmodontinos, como así también especímenes atribuibles a las familias Caviidae y Ctenomiydae. Solo dos restos corresponden a alguna especie de marmosino (Tabla 1). Entre los elementos anatómicos recuperados se registra un marcado predominio de mandíbulas $(\mathrm{Ri}=93,75 \%)$ y fémures $(\mathrm{Ri}=90,62 \%)$, seguidos por húmeros $(\mathrm{Ri}=$ $59,37 \%$ ) y maxilas ( $\mathrm{Ri}=56,25 \%)$, en tanto se observa una ausencia de huesos del autopodio. Respecto a

Tabla 1. Composición taxonómica del conjunto óseo recuperado en la cuadrícula 2 del Alero 2 (NA= no aplica). Taxonomic composition of the bone assemblage recovered in grid 2 of Alero $2(N A=$ not applicable $)$.

\begin{tabular}{cccc}
\hline Taxa & NISP & NISP\% & MNI \\
\hline Didelphidae & 2 & 1 & 1 \\
\hline Rodentia & 86 & 43,9 & NA \\
\hline Ctenomys sp. & 22 & 11,2 & 4 \\
\hline Caviinae & 17 & 8,7 & 3 \\
\hline Cricetidae & 49 & 25 & NA \\
\hline Akodon sp. & 2 & 1 & 1 \\
\hline $\begin{array}{c}\text { Eligmodontia sp. } \\
\text { Reithrodon auritus }\end{array}$ & 71 & 5,6 & 5 \\
\hline Total & 196 & 100 & 17 \\
\hline $\begin{array}{c}\text { Restos óseos } \\
\text { indeterminados }\end{array}$ & 21 & & \\
\hline
\end{tabular}

estos últimos, podría existir un sesgo generado por las técnicas de recuperación en zaranda dado su tamaño muy pequeño. Los carboncitos a lo largo de la estratigrafía ( $\sin$ considerar las lentes) fueron más escasos en esta cuadrícula. Los niveles 6, 7, 8 y 10 resultaron casi estériles (escasos microcarbones).

\section{Estratigrafía, análisis texturales y geoquímicos}

Las excavaciones permitieron exponer una secuencia sedimentaria conformada por el desprendimiento de clastos angulosos procedentes del techo y paredes del alero que, con el transcurso del tiempo, generaron acumulaciones de derrubio con algunas variaciones de tamaño a lo largo del perfil. Estas variaciones podrían corresponder a pequeños cambios en la textura o estructura de la riolita de caja. La predominancia de este derrubio generó una fábrica abierta, clasto sostén, con una matriz fina subordinada conformada por arena fina y limo, que en parte correspondería al aporte eólico y en parte a la meteorización del detrito riolítico. La falta de cohesión entre la fracción fina y los clastos desprendidos de la roca de caja hace que la consistencia del relleno matriz sea friable, dificultando la estabilidad de los perfiles una vez expuestos. Las condiciones de sedimentación con predominio del aporte autóctono, se han mantenido a lo largo del tiempo y no se observan rasgos pedológicos, a excepción de algunas raicillas. La estratificación es de tipo horizontal, con un leve buzamiento de las capas hacia el exterior del alero, que se hace más marcado al aproximarse a la base del relleno, en correspondencia con la inclinación del fondo rocoso. Las delgadas lentes de carbón y cenizas registradas, aunque discontinuas lateralmente, colaboran también en separar eventos depositacionales (Figura 6).

Para los análisis texturales se tomaron muestras de sedimento en la cuadrícula 2, a 20,55 y $95 \mathrm{~cm}$ de la superficie. Estos fueron tamizados con mallas de $2 \mathrm{~mm}, 1 \mathrm{~mm}, 0,42 \mathrm{~mm}$ y $0,075 \mathrm{~mm}$ de apertura, obteniéndose los resultados presentados en la Figura 7.

La Figura 7 muestra que la proporción de sedimentos mayores a $2 \mathrm{~mm}$ (gravilla angulosa de la roca de caja) se incrementa con la profundidad, mientras decrecen los finos. En la fracción menor a $1 \mathrm{~mm}$ se ubicarían los sedimentos movilizados en suspensión por el viento, junto a los productos de la meteorización del derrubio. Esta fracción fina posee porcentajes entre 24 y $29 \%$ en las muestras analizadas. 


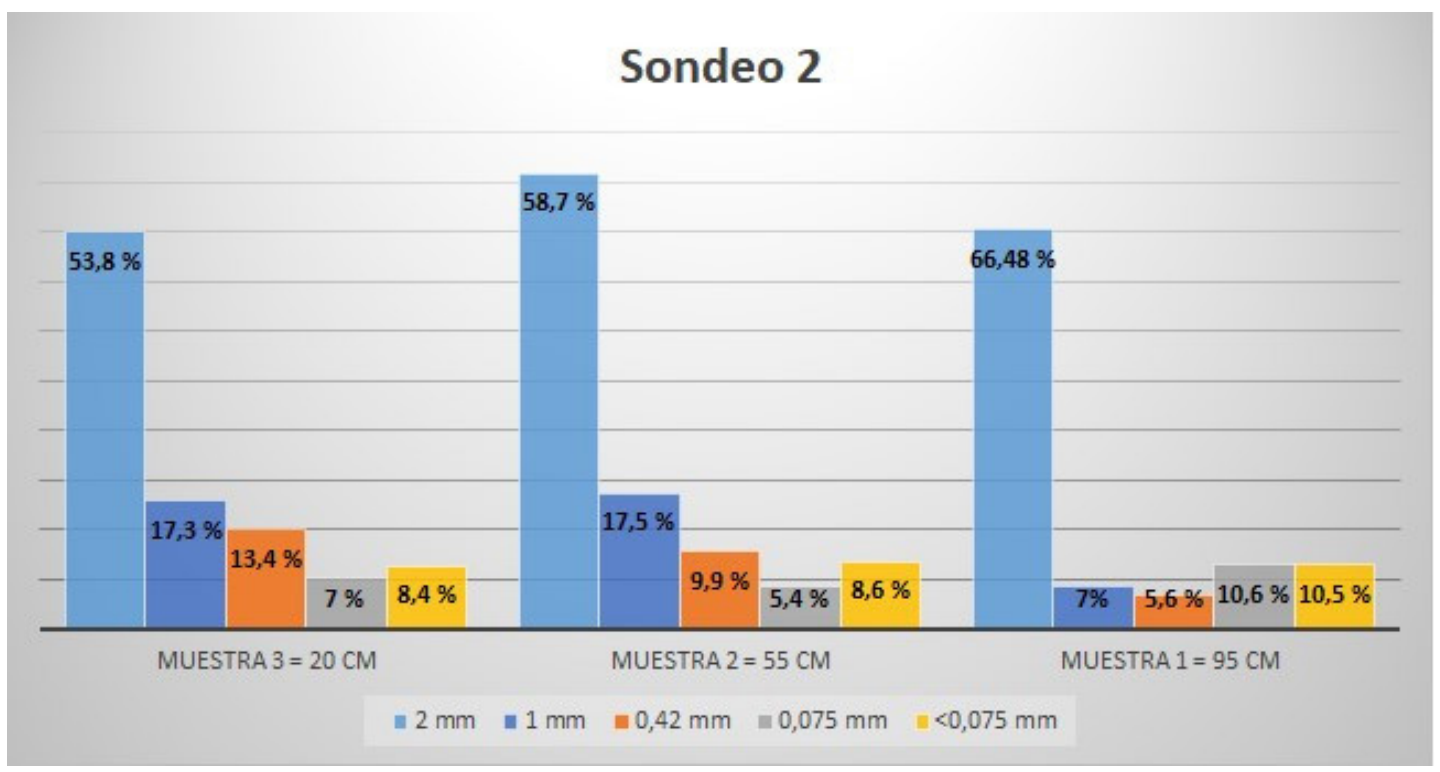

Figura 7. Distribución porcentual de las muestras por tamaño de grano.

Percentage distribution of samples by grain size.

Un análisis más detallado, por difractometría láser, de esta fracción (Figura 8) indica para las muestras 1 y 2 $(95$ y $55 \mathrm{~cm})$ una moda principal en la fracción limo grueso a arena fina, con buena selección, consistente con un origen eólico. No obstante, habría que evaluar si ello puede resultar también (al menos en parte) de los procesos de meteorización. En el caso de la fracción arcillosa, es probable que corresponda a los productos de la hidrólisis de los silicatos presentes en la riolita. En la parte superior $(20 \mathrm{~cm})$ la moda predominante se encuentra en la fracción arena media. No es claro el origen de esta segunda moda, pero podría corresponder al aporte de la fragmentación de los clastos in situ, que transformó parte de la fracción gruesa original, por meteorización y/o pisoteo, en esta moda de arena media. Este proceso pudo ser favorecido por las tasas muy bajas de sedimentación registradas en el sector superior de esta columna. En cualquier caso, se deben realizar más estudios granulométricos y composicionales en esta y otras secuencias del área para determinar con mayor precisión los procesos sedimentarios involucrados, así como una evaluación de los productos derivados de la meteorización de la riolita.

Por otro lado, se realizaron estudios geoquímicos que tuvieron como objetivo principal evaluar las condiciones de preservación de los materiales arqueológicos de origen orgánico en la estratigrafía. Estos consistieron en análisis de sales predominantes y de $\mathrm{pH}$ (Tabla 2 y Figura 9).

De acuerdo con la Tabla 2 y la Figura 9 las sales solubles mayoritarias son cloruros y sulfatos de sodio. Estas también resultan mayoritarias en el agua de mar (Porras Martin et al. 1985), por lo que se considera que fueron transportadas al alero por la bruma marina. Estas sales son muy abundantes en la parte superior del perfil en la cuadrícula 2 , en cambio, en la cuadrícula $1(\mathrm{C} 10-20 \mathrm{~cm})$ sus valores se ven muy reducidos. Tal diferencia podría vincularse con tasas de sedimentación más elevadas en este último caso, que no habrían facilitado su concentración (ver Cronología y tasas de sedimentación), o también con que los procesos de transporte de sales o de humedad por el viento hayan afectado en forma diferente a cada cuadrícula. La Figura 9 muestra los cambios con la profundidad en la cuadrícula 2. El bicarbonato actúa como base débil y el amonio como ácido débil, de esta manera al descender el bicarbonato con la profundidad el $\mathrm{pH}$ sigue la misma tendencia. No obstante, en el primer punto $(10 \mathrm{~cm})$ el $\mathrm{pH}$ resulta más bajo de lo esperado a partir de la concentración de bicarbonato, lo que podría deberse a que allí hay una cantidad algo mayor de amonio. Este último es generalmente asociado con la excreta animal, que en 

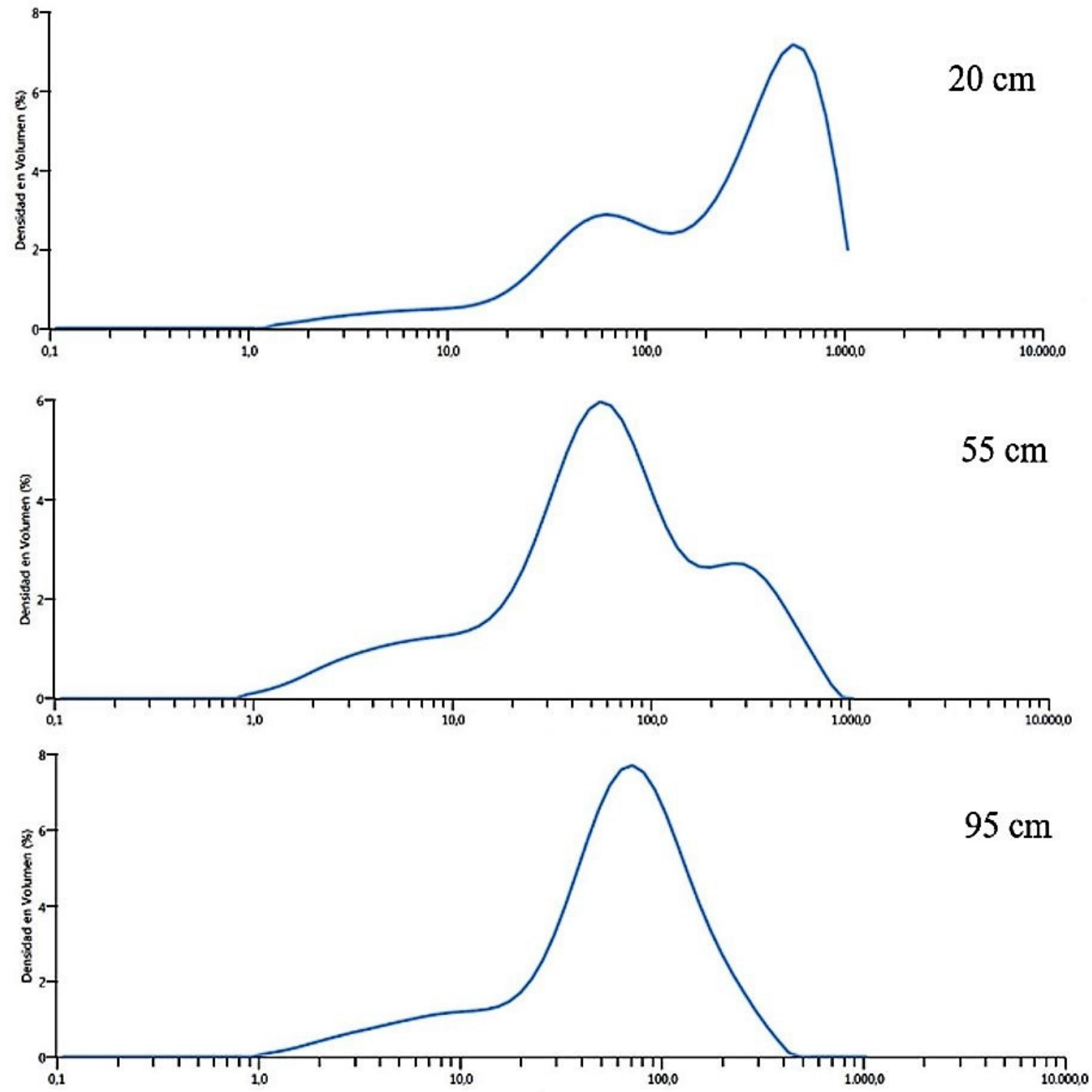

micrones

Figura 8. Curvas granulométricas (fracción $<1 \mathrm{~mm}$ ) obtenidas por difractometría láser.

Granulometric curves (<1mm fraction) obtained by laser diffractometry.

Tabla 2. Iones presentes en las sales solubles en muestras de las cuadrículas 1 y 2. Se indican también los valores de $\mathrm{pH}$ asociados.

Ions present in soluble salts in samples from grids 1 and 2. Associated $\mathrm{pH}$ values are also indicated.

\begin{tabular}{|c|c|c|c|c|c|c|c|c|c|c|c|}
\hline $\begin{array}{l}\text { Profundidad } \\
\text { muestra }\end{array}$ & $\mathrm{Cl}^{-}(\mathrm{mg} / \mathrm{g})$ & $\begin{array}{c}\mathrm{Ca}^{2+} \\
(\mathrm{mg} / \mathrm{g})\end{array}$ & $\begin{array}{l}\mathrm{Mg}^{2+} \\
(\mathrm{mg} / \mathrm{g})\end{array}$ & $\begin{array}{c}\mathrm{Na}^{+} \\
(\mathrm{mg} / \mathrm{g})\end{array}$ & $\begin{array}{c}\mathrm{K}^{+} \\
(\mathrm{mg} / \mathrm{g})\end{array}$ & $\begin{array}{l}\mathrm{HCO}_{3}^{-} \\
(\mathrm{mg} / \mathrm{g})\end{array}$ & $\begin{array}{c}\mathrm{NH}_{4}^{+} \\
(\mathrm{mg} / \mathrm{g})\end{array}$ & $\begin{array}{l}\mathrm{NO}_{3}^{-} \\
(\mathrm{mg} / \mathrm{g})\end{array}$ & $\begin{array}{c}\mathrm{NO}_{2}^{-} \\
(\mathrm{mg} / \mathrm{g})\end{array}$ & $\begin{array}{l}\mathrm{SO}_{4}= \\
(\mathrm{mg} / \mathrm{g})\end{array}$ & $\begin{array}{c}\mathrm{pH} \\
(2: 1)\end{array}$ \\
\hline C1 $0-20$ & 5,683 & 1,976 & 1,928 & 4,04 & 0,084 & 1,105 & 0,22 & 0,175 & 0,064 & 0,163 & 7,26 \\
\hline C2 $0-10$ & 30,84 & 3,78 & 2,534 & 15,3 & 0,139 & 3,916 & 0,06 & 1,385 & 0,25 & 65,16 & 6,99 \\
\hline C2 20 & 20,964 & 4,132 & 3,845 & 10,65 & 0,086 & 1,34 & 0,39 & 0,077 & 0,071 & 47,74 & 7,99 \\
\hline C2 55 & 4,235 & 2,466 & 0,705 & 4,02 & 0,054 & 0,711 & 0,055 & 0,347 & 0,007 & 18,003 & 7,67 \\
\hline C2 95 & 0,565 & 0,046 & 1,515 & 1,3 & 0,01 & 0,27 & 0,13 & 0,167 & 0,002 & 9,258 & 6,15 \\
\hline
\end{tabular}




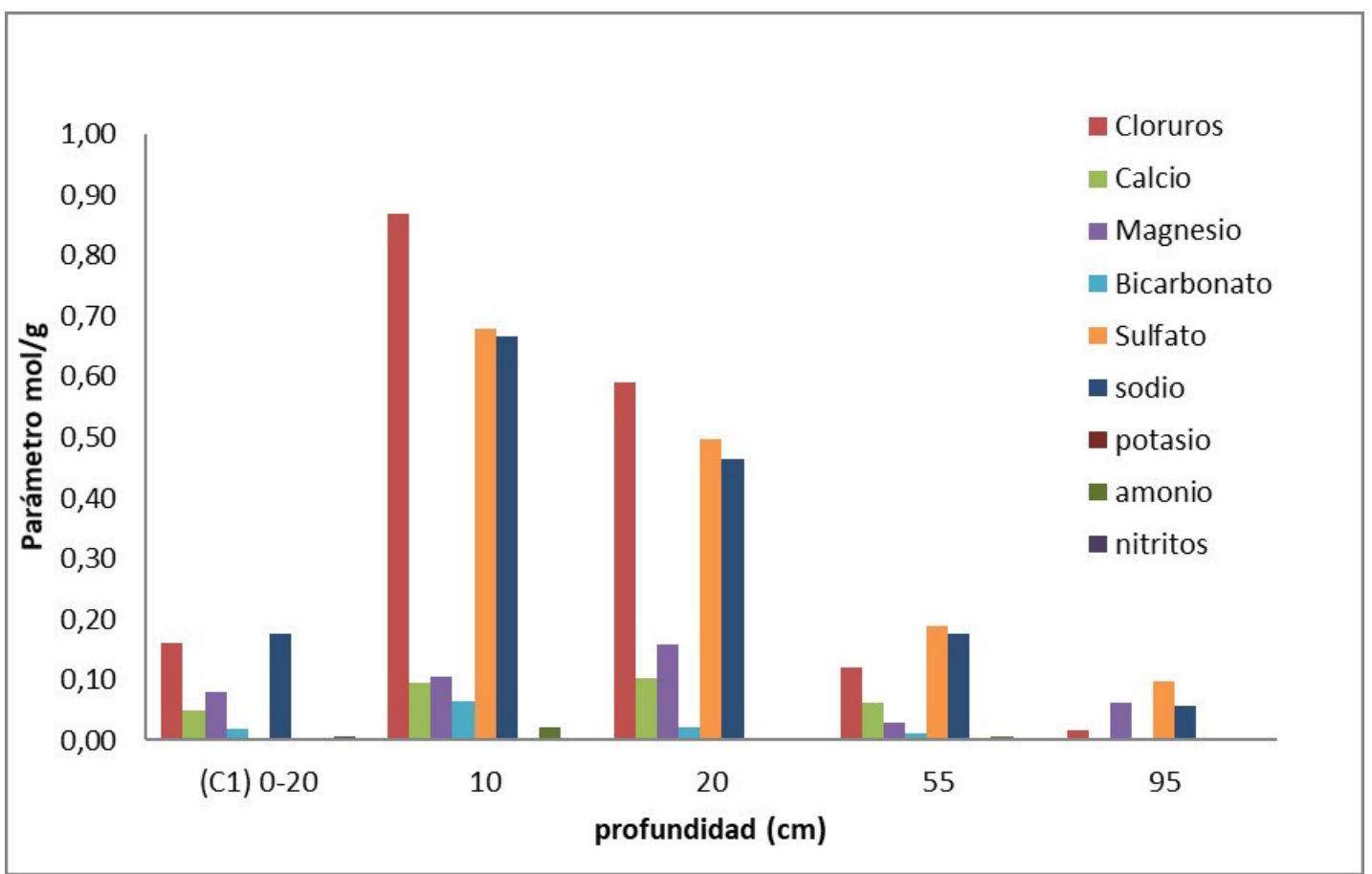

Figura 9. Distribución en moles/g de los iones representados en las cuadrículas 1 y 2.

Distribution in moles/g of ions in samples from grids 1 and 2.

este caso podría corresponder a aves dado el registro de sus actividades en el alero y la presencia de guano de este origen en la actualidad.

\section{Cronología y tasas de sedimentación}

Como se ha mencionado, la matriz sedimentaria se halla constituida esencialmente por derrubio tamaño gravilla procedente de la disgregación de la roca del alero (material autóctono), con una fracción fina limo-arenosa muy subordinada ( 24 a $29 \%$ en peso) de origen parcialmente eólico. Al haber sido la meteorización de la riolita la principal fuente de material clástico, la tasa de aporte sedimentario podría considerarse lenta a muy lenta en promedio. Las dataciones radiocarbónicas obtenidas en el Alero 2 (Tabla 3) permiten, aún con limitaciones, expresar esas tasas de sedimentación en términos numéricos.

Considerando los valores medios de las edades calibradas y de los rangos de profundidad (ambos indicados entre paréntesis en la Tabla 2), se puede estimar el tiempo transcurrido en relación con el sedimento acumulado. De esta forma, transcurrieron en promedio unos 80 años por cada centímetro depositado en la cuadrícula 1 (5100 años en $55 \mathrm{~cm}$ ) y unos 90 años por cada centímetro depositado en la cuadrícula 2 (7500 años en $95 \mathrm{~cm}$ ). No obstante, en la cuadrícula 2 existen diferencias entre la parte superior e inferior de la secuencia. Los primeros 36 $\mathrm{cm}$, asumiendo que no hubo remoción de sedimentos, se habrían depositado en unos 5500 años (tasa de 153 años por $\mathrm{cm}$ de sedimento) y los siguientes $60 \mathrm{~cm}$ en unos 2000 años (tasa de solo 33 años por $\mathrm{cm}$ ). En la cuadrícula 1, en cambio, no hay tanta diferencia entre los primeros $20 \mathrm{~cm}$ y los siguientes $35 \mathrm{~cm}$ de acuerdo con las dataciones, que proporcionan tasas de 110 y 83 años por cm en cada caso.

En conjunto y considerando ambas cuadrículas, estas tasas sugieren una sedimentación predominantemente lenta, coherente con el origen autóctono de los sedimentos que dominan en el relleno del alero. No obstante, el cálculo de tasas numéricas resulta siempre un tanto ficticio porque la sedimentación no es constante. Existen discontinuidades de origen natural y cultural que consumen tiempo y pueden ser evidentes o no en la estratigrafía (i.e., periodos sin sedimentación, remoción antrópica de relleno para el acondicionamiento del espacio o por limpieza de 
Tabla 3. Edades ${ }^{14} \mathrm{C}$ obtenidas en el Alero 2 sobre muestras de carbón.

${ }^{14} \mathrm{C}$ Ages obtained on charcoal samples in Alero 2.

\begin{tabular}{cccccc}
\hline $\begin{array}{c}\text { Cuadrícula y } \\
\text { profundidad }\end{array}$ & $\begin{array}{c}\text { Edad }{ }^{14} \text { C obtenida } \\
(\text { años AP) }\end{array}$ & $\begin{array}{c}{ }^{13} \mathrm{C} \\
(\%)\end{array}$ & $\mathrm{N}^{\circ}$ Lab. & $\begin{array}{c}\text { Rango calibrado y valor } \\
\text { medio (años AP) }\end{array}$ & Referencias \\
\hline $\begin{array}{c}1-19-22 \mathrm{~cm} \\
(20 \mathrm{~cm})\end{array}$ & $2240 \pm 80$ & $-24^{*}$ & LP3611 & $\begin{array}{c}2106-2318 \\
(2203)\end{array}$ & Este trabajo \\
\hline $\begin{array}{c}1-50-60 \mathrm{~cm} \\
(55 \mathrm{~cm})\end{array}$ & $4560 \pm 100$ & $-24^{*}$ & LP3449 & $\begin{array}{c}4980-5314 \\
(5159)\end{array}$ & Carranza y Cardillo 2019 \\
\hline $\begin{array}{c}2-35-37 \mathrm{~cm} \\
(36 \mathrm{~cm})\end{array}$ & $4800 \pm 100$ & $-24^{*}$ & LP3569 & $\begin{array}{c}5326-5591 \\
(5483)\end{array}$ & Este trabajo \\
\hline $\begin{array}{c}2-90-100 \mathrm{~cm} \\
(95 \mathrm{~cm})\end{array}$ & $6624 \pm 31$ & No informado & D-AMS 026733 & $\begin{array}{c}7435-7503 \\
(7480)\end{array}$ & Carranza y Cardillo 2019 \\
\hline
\end{tabular}

* Valor determinado por el laboratorio.

fogones, su dispersión por pisoteo, etc.), requiriéndose a veces estudios específicos para detectarlas. De esta manera las tasas numéricas representan solo una aproximación. Si pudieran datarse todos los niveles en los que se registran carboncitos se podría obtener una mejor imagen del proceso de sedimentación y sus discontinuidades en cada cuadrícula, a la vez que ello colaboraría en indicar algún posible proceso de perturbación en la secuencia (Straus 1990). Fuera de esto, a partir de la cronología obtenida puede decirse que este alero fue utilizado en forma periódica, aunque no intensa, al menos entre unos 2200 y unos 7500 años calibrados antes del presente (Tabla 2).

\section{Discusión}

Ha sido necesaria una conjugación de agentes externos e internos (propios de la roca de caja) para que los afloramientos rocosos de Punta Pórfido desarrollen oquedades. Este proceso evolucionó a lo largo del tiempo bajo la acción de la meteorización y la erosión hasta que las rocas se transformaron lo suficiente para evolucionar en espacios aptos para la ocupación humana (aleros). Desde las etapas iniciales estas oquedades pudieron registrar uso por parte de distintas especies que habitan el área, principalmente aves de acuerdo con lo registrado al momento (i.e., guano, plumas y egagrópilas). En la etapa de ocupación humana esta información tafonómica se suma a la de origen antrópico, constituyendo un registro paleoecológico de las interacciones humano-ambiente en esos espacios acotados.
Para que las cavidades puedan ser habitadas por lo humanos en alguna etapa de su evolución deben ofrecer condiciones atractivas respecto a su tamaño, acceso, localización, función particular buscada, factores idiosincráticos, etc. ofreciendo a la vez cierto grado de protección de los agentes externos (i.e., temperaturas, sol, lluvias, vientos). Paralelamente, estos espacios resultan adecuados para que aves que frecuentan el área como jotes o lechuzas de campanario los ocupen y regurgiten allí los restos de sus presas, generando importantes acumulaciones óseas de pequeños vertebrados (Andrews 1990). La presencia de egagrópilas en diferentes estados de preservación (de manera compacta y/o parcial o totalmente desagregadas) tanto en superficie como en el relleno del Alero 2, da cuenta de la persistencia en el uso de este espacio por las aves, posiblemente en forma alternada con los seres humanos. Entre los restos óseos recuperados se observa un marcado predominio de microvertebrados, representados mayormente por pequeños roedores. Dicha representación taxonómica es consistente con la alimentación de Strigiformes como Tyto furcata, que se nutre principalmente de micromamíferos y, en menor medida, de otros microvertebrados e insectos (Bellocq 2000). Asimismo, el análisis tafonómico realizado sobre los restos muestra una buena preservación con un bajo grado de modificación. Esto, sumado a la presencia de especímenes óseos y dentarios con evidencias de corrosión digestiva mayormente del tipo ligera, sugiere que las rapaces nocturnas serían el principal agente responsable de la acumulación de los restos de pequeños vertebrados en el relleno, 
descartando, por el momento, la intervención de otros potenciales agentes como los jotes que suelen consumir carroña preferentemente de animales de mediano y gran porte y generar mayores grados de corrosión gástrica (Ballejo et al. 2012). El ingreso de los restos de microvertebrados al depósito por causas eto-ecológicas es menos probable dado que no se han recuperado elementos completos en posición anatómica y/o articulados, no se han observado cuevas (a excepción de una probable) y el relleno del alero, pese a ser friable, se observa estratificado, lo que sugiere un bajo impacto de la actividad de animales fosoriales.

Las bajas tasas de sedimentación resultan predominantes en el alero, no obstante, las edades radiocarbónicas sugieren diferencias entre la parte superior y la inferior de la secuencia estratigráfica excavada en el sector 1 (cuadrícula 2). Una sedimentación muy lenta, entre otros factores, ayudaría a explicar la mayor presencia de sales en la parte superior de este perfil, dando origen a costras y concreciones salinas. Bajo las condiciones ambientales y geoquímicas imperantes, esta baja sedimentación no dio lugar a procesos de pedogénesis. En la cuadrícula 1, las tasas relativas más elevadas habrían favorecido una mejor preservación de egagrópilas, aún reconocibles como tales en la estratigrafía. Asimismo, por factores tafonómicos, el enterramiento de los huesos pequeños resulta normalmente más rápido que el de los huesos grandes (Behrensmeyer 1978).

Las diferencias en las tasas de sedimentación entre las cuadrículas 1 y 2 son interesantes, ya que ilustran los cambios que se producen en las condiciones de agradación tanto entre distintos sectores del alero como en un mismo sector a lo largo del tiempo. En ello interviene la propia evolución de la cavidad, que va modificando su geometría, hecho que genera cambios en el aporte por meteorización de la roca de caja entre sectores, y en un mismo punto, con el transcurso del tiempo. A esto se suman posibles diferencias en cuanto al aporte eólico (aunque pueda ser modesto en este caso) en cada sector. Este aporte es también dependiente de los cambios en la morfología de la cavidad, incluyendo variables microtopográficas, asî como de modificaciones en la orientación del frente y la dinámica ambiental circundante.

Resulta interesante que con las muy bajas tasas de sedimentación predominantes en el Alero 2 los restos de pequeños vertebrados se hayan preservado tan bien. Es posible que dentro del reparo se haya generado un microambiente amortiguado que retardó el deterioro de los huesos en superficie. A ello seguramente contribuyó el clima (fresco y seco) y la protección frente a la radiación solar, al viento y a los cambios bruscos de temperatura. También pudo haber tenido un papel el pisoteo, que colaboraría con una incorporación más rápida al sustrato, como indican los estudios experimentales (p.e.j., Gifford-Gonzalez et al. 1985; Nielsen 1991). Los ambientes reparados pueden generar secuencias de meteorización muy diferentes a las consideradas en contextos de sitios a cielo abierto. Un caso extremo lo constituyen los hallazgos en cavidades bajo condiciones muy frías y secas, como ocurre en Última Esperanza (Chile). En esta región, en una cámara interior de la Cueva Lago Sofía 4 se han hallado huesos de fauna pleistocena preservados en superficie sin evidencias de meteorización (Borrero et al. 1997; Favier Dubois y Borrero 1997).

La secuencia estratigráfica del Alero 2 se observa bien preservada. Si bien en un principio se supuso que la presencia de numerosos restos de roedores en el relleno podría indicar procesos de mezcla, ello no se correspondía con la estratificación horizontal bien conservada (Figura 6). Asimismo, pronto se vio que la gran mayoría de esos restos tendría su procedencia en egagrópilas disgregadas, depositadas originalmente en superficie. Respecto al material cultural recuperado, los artefactos líticos han sido muy escasos en estratigrafía, consistiendo básicamente en lascas y microlascas y un solo instrumento. Los artefactos recuperados, así como la ausencia de núcleos y la baja incidencia de corteza, sugieren un ingreso al alero con artefactos ya formatizados en donde se realizaron posiblemente tareas de mantenimiento. Por otra parte, durante las excavaciones se observó que una parte del registro lítico recuperado no presentaba atributos tecnológicos claros y que dichos materiales correspondían a la materia prima de la que está conformada el alero. Esto promovió realizar un estudio experimental a escala del sitio (Carranza y Cardillo 2019) en vistas a que la riolita local, si bien no es de buena calidad para la talla, posee fractura concoide y el potencial de simular lascados. Los resultados obtenidos no descartan que la caída de rocas pueda generar pseudo-artefactos por impacto (no observados durante el experimento), pero sí soportan la interpretación del origen antrópico de los materiales confeccionados con la roca de caja del alero, que presentan claros atributos vinculados a la talla por percusión directa. 
En relación con los materiales orgánicos de origen cultural, estos se hallan representados por los carbones de los fogones, así como por los gasterópodos y los fragmentos de valvas marinas, que, al menos que las aves pudieran movilizarlos, se consideran de descarte antrópico. El resto óseo humano es otro indicador de su presencia en el sitio, mientras que el fragmento de cáscara de huevo y las plumas podrían ser de origen natural.

Los niveles de carbones y cenizas parecen corresponder a eventos de combustión, dispersos por el pisoteo y otros procesos de superficie en forma previa a su entierro, generando lentes delgadas y alargadas. Resultan muy similares a los "fogones planos" que mencionan Zubimendi y Ambrústolo (2016) en el relevamiento sistemático de abrigos rocosos que efectuaron en la costa norte de Santa Cruz (Patagonia austral argentina). Su escasa superposición en la estratigrafía del Alero 2 y la casi ausencia de registro asociado a ellos indicaría ocupaciones poco redundantes y de corta duración. Si bien las excavaciones fueron acotadas $\left(1,6 \mathrm{~m}^{2}\right)$, la evidencia obtenida apuntaría a un uso esporádico y muy efímero de este espacio. El empleo para la talla de una roca inmediatamente disponible y de otras rocas de menor calidad de origen local, como el cuarzo y la pizarra, sugieren estrategias oportunistas combinadas con el trasporte de artefactos formatizados de mayor calidad (Carranza y Cardillo 2019). Respecto al registro de representaciones rupestres, no se han documentado al momento en el área de Punta Pórfido, pero se han reconocido algunas pinturas en serranías con afloramientos de riolitas ubicados unos kilómetros al noroeste de esta localidad (aún inéditas).

Teniendo en consideración la cronología máxima obtenida en la base del alero, una pregunta que surge es por qué su relleno se habría iniciado en el Holoceno Medio. Una posible explicación es que el alero haya comenzado a acumular sedimentos recién en ese entonces. Otra alternativa es que un posible relleno más temprano haya sido erosionado. Una observación que efectuamos en los afloramientos cercanos al alero resulta pertinente para el caso. Por lo general los tafoni no poseen relleno o este es muy escaso mientras ocupan diversas posiciones a diferentes alturas en los frentes rocosos. Eso ocurre en forma independiente de su tamaño, es decir, aunque sean grandes cavidades (aptas como alero) no presentan relleno en tales situaciones o este es escaso. Al parecer, la acumulación de relleno comienza a ser significativa en aquellas cavidades que tomaron contacto con el terreno en la base de los afloramientos o con un talud de derrubios (como acontece en el caso del Alero 2, Figura 5). Esta situación topográfica les permite retener y acumular sedimentos. En el caso del Alero 2 tal circunstancia pudo haber ocurrido recién en el Holoceno Medio, iniciándose en esa etapa su relleno y el potencial de preservar el registro de ocupaciones humanas.

Respecto a los procesos de erosión que los afectan, hemos observado también en el área de estudio que el relleno sedimentario puede ser removido de las oquedades y aleros que se hallan en posiciones elevadas en los afloramientos rocosos. Este relleno, aunque resulte poco desarrollado, en ocasiones incluye material arqueológico que repta y se canaliza por los drenajes labrados entre las rocas (Figura 10). De esta manera, los cambios que se producen como parte del retroceso normal de los frentes rocosos pueden conducir a procesos de erosión y lavado del relleno de las oquedades y aleros más expuestos. Este fenómeno resultaría poco probable en las situaciones topográficas mencionadas de pie de afloramiento o de contacto con un talud. Asimismo, la presencia de vegetación en el frente de algunos tafoni colabora en la retención temporal de su relleno, pero este nunca llega a ser importante si no se desarrolla en las situaciones favorecedoras referidas.

El fechado de ca. 7500 años cal. AP obtenido en la base de la cuadrícula 2 del alero corresponde a un momento cercano al inicio del relleno en este reparo, pero que no necesariamente coincide con el comienzo de la ocupación humana del sector. La cronología máxima a obtenerse en otras cavidades de la región puede ser mayor, dado que solo se halla condicionada por la preservación de rellenos antiguos (Holoceno inferior o Pleistoceno superior) que contengan evidencia orgánica datable (sea de origen antrópico o no) que permita corroborar su antigüedad. Estos depósitos podrían eventualmente hallarse presentes en aleros ya colapsados o colmatados, poco o nada visibles en la actualidad. Este hecho siempre debe ser considerado en una investigación regional (ver Borrero et al. 2007) y requiere del uso de metodologías geoarqueológicas orientadas a la detección de posibles casos. Aún no hemos registrado situaciones sugerentes a este respecto en Punta Pórfido, no obstante, el fechado obtenido en la base del Alero 2 representa una de las dos edades 


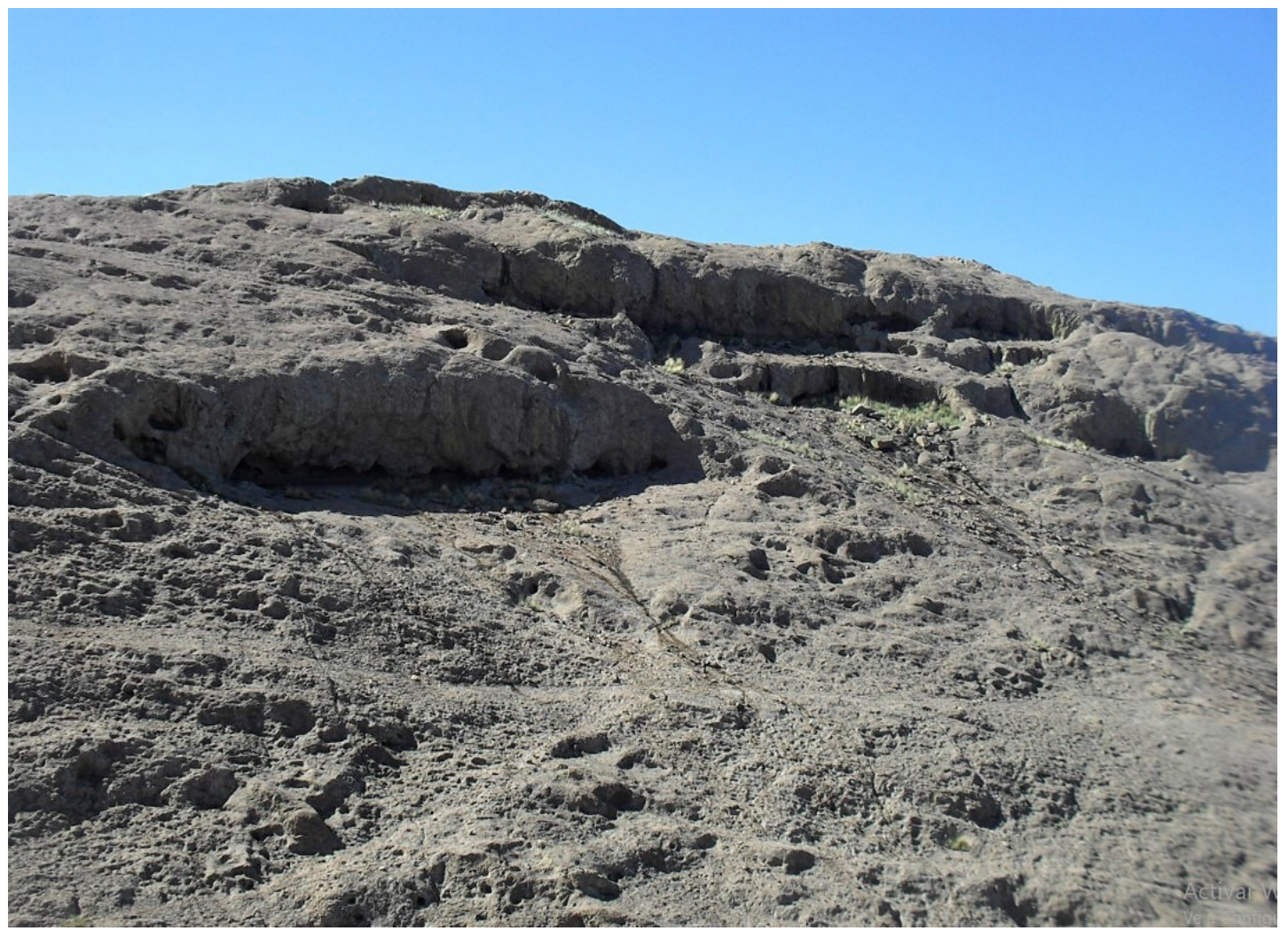

Figura 10. Efecto de la erosión en los frentes rocosos que da lugar a la pérdida del relleno de los reparos.

Erosion processes in the rocky fronts that lead to the shelters fillings loss.

más antiguas obtenidas en el litoral rionegrino (Favier Dubois 2019), destacando el potencial cronológico de estas geoformas.

\section{Conclusiones}

Los afloramientos rocosos de Punta Pórfido proporcionan un interesante panorama acerca de los procesos de meteorización/erosión en esta localidad y la formación de oquedades y aleros. Permiten evaluar comparativamente la generación de rellenos y los procesos que pudieron afectarlos a lo largo del tiempo. Esto resulta útil para interpretar las secuencias arqueológicas excavadas en tales contextos, así como para evaluar su contenido tafonómico y las cronologías radiocarbónicas obtenidas en ellas. Los resultados presentados aquí son iniciales, pero puede decirse que las cavidades rocosas en Punta Pórfido tienen un interesante potencial para la preservación de evidencia orgánica, facilitada por variables climáticas locales y la presencia de sales en sus rellenos; tal evidencia podría incluir la de los momentos de ocupación iniciales de la región. Estos lugares representan asimismo un interesante reservorio de datos paleoecológicos procedentes tanto de las evidencias generadas por los seres humanos como por parte de la fauna local (i.e., egagrópilas y guano de aves, excrementos de zorro), que aún deben estudiarse con mayor profundidad.

El Alero 2 registra ocupaciones humanas a partir de 7500 años cal. AP, lo que muestra que los ambientes de aleros en Punta Pórfido no han sufrido los sesgos de erosión o falta de sedimentación que afectaron a los depósitos eólicos y coluviales en otros sectores del litoral rionegrino (Favier Dubois 2013, 2019) disminuyendo la señal antrópica del Holoceno medio. Existen sesgos específicos de estas geoformas, como los vinculados al inicio y preservación de sus rellenos, pero, pese a ello, constituyen espacios de acumulación con mucho potencial para contribuir al panorama cronológico regional. Asimismo, los aleros proveen valiosa información acerca de los modos de ocupación del espacio y utilización de recursos 
que se suma a las evidencias procedentes de otras unidades del paisaje costero. Todo esto proporciona una idea más completa de las interacciones entre los seres humanos y sus ambientes a lo largo del tiempo en esta región.

Agradecimientos: Estas investigaciones fueron financiadas por los Proyectos PIP CONICET 00756 y
00589 y ANPCYT PICT 2013 1128. A las Licenciadas Eugenia Carranza y Rocío Guichón por su colaboración durante las excavaciones. Al Dr. Manuel López quién contribuyó en las determinaciones de algunas especies de roedores. A la Lic. Daniela Storchi Lobos por la lectura crítica y sugerencias al manuscrito. Finalmente, a los evaluadores anónimos del artículo quienes han colaborado mucho en mejorarlo.

\section{Referencias Citadas}

Alquiza, P., M. Gómez Peralta, M. Avilés, V. Reyes, M. Hernández y V. Ordaz 2015. El rol de las comunidades de líquenes en el deterioro superficial de su substrato rocoso: estudio de la interfase liquen-roca en dos monumentos históricos de la ciudad de Guanajuato, México. Acta Universitaria 25 (4):35-47.

Andrews, P. 1990. Owls, Caves and Fossils. The University of Chicago Press, Chicago.

Ballejo, F., F. Fernández y L. De Santis 2012. Tafonomía de restos óseos provenientes de egagrópilas de Coragyps atratus (jote de cabeza negra) en el noroeste de la Patagonia Argentina. Revista del Museo de Antropología 5 (1):213-222.

Bellocq, M.I. 2000. A review of the trophic ecology of the barn owl in Argentina. Journal of Raptor Research 34 (2):108-119.

Behrensmeyer A.K. 1978. Taphonomic and ecologic information from bone weathering. Paleobiology 4:150-162.

Borella, F., M. Cardillo, C.M. Favier Dubois y J. Alberti 2015 Nuevas investigaciones arqueológicas entre Punta Pórfido y Punta Odriozola: implicancias para el entendimiento de la dinámica de las ocupaciones humanas en la costa oeste del golfo San Matías (Río Negro). Relaciones de la Sociedad Argentina de Antropología XL (1):233-252.

Borrero, L.A., F. Martin y A. Prieto 1997. La Cueva Lagos Sofía 4, Última Esperanza, Chile. Una madriguera de felino del Pleistoceno tardío. Anales del Instituto de la Patagonia, Serie Ciencias Humanas 25:103-122.

Borrero, L., R. Barberena, F. Martin y K. Borrazzo 2007. Collapsed rockshelters in Patagonia. En On Shelter's Ledge: Histories, Theories, and Methods of Rockshelter Research, editado por M. Kornfeld, S. Vasilev y L. Miotti, pp. 135-139. BAR International Series 1655. Archaeopress, Oxford.

Busteros, A.G., R.E. Giacosa, H.A. Lema y M.A. Zubía 1998. Hoja Geológica 4166-IV Sierra Grande. Provincia de Río Negro. Programa Nacional de Cartas Geológicas de la República Argentina 1:250.000. Servicio Geológico Minero Argentino. Instituto de Geología y Recursos Minerales, Buenos Aires.

Cabrera, A.L. y A. Willink 1980. Biogeografía de América Latina. Monografías de la OEA, Washington D.C.

Carranza, E. y M. Cardillo 2019. Desprendimientos rocosos y ruido tafonómico: trabajo experimental en el Alero 2 de Punta Pórfido, Golfo San Matías (Provincia de Río Negro, Argentina). Chungara Revista de Antropología 51 (4):559-571.

Cortés, J.M. 1981. El sustrato precretácico del extremo noreste de la provincia del Chubut. Revista de la Asociación Geológica Argentina (RAGA) XXXVI (3):217-235.
Crisoliti, L.E. y M.E. Pahissa Campá 1973. Análisis climáticos de las estaciones meteorológicas Patagones, San Antonio Oeste y Trelew. En Relevamiento Ecológico y Tipificación de las Comunidades del Litoral Marítimo de la Provincia de Río Negro, con Especial Referencia al Establecimiento de Áreas de Cultivo para Especies de Interés Comercial, pp. 13-88. Instituto de Biología Marina. Asesoría de desarrollo de Río Negro. Consejo Federal de Inversiones. Director del programa: Santiago R. Olivier. Disponible en Biblioteca del Consejo Federal de Inversiones (Capital Federal).

De Alba, E. 1964. Descripción Geológica de la Hoja 41 j, Sierra Grande. Escala 1:200.000. Carta Geológico-Económica de la República Argentina. Provincia de Río Negro. Dirección Nacional de Geología y Minería, Buenos Aires.

Farrand, W.R. 1985. Rockshelter and cave sediments. En Archaeological Sediments in Context, editado por J.K. Stein y W.R. Farrand, pp. 21-40. Center for the Study of Early Man, Orono.

Farrand, W. 2001. Archaeological sediments in rockshelters and caves. En Sediments in Archaeological Context, editado por J.K. Stein y W.R. Farrand, pp. 29-66. University of Utah Press, Salt Lake City.

Favier Dubois, C.M. y L.A. Borrero 1997. Geoarchaeological perspectives on Late Pleistocene faunas from Ultima Esperanza Sound, Magallanes, Chile. Anthropologie, International Journal of the Science of Man XXXV (2):207-213.

Favier Dubois, C.M., F. Borella y R. Tykot 2009. Explorando tendencias en el uso humano del espacio y los recursos en el litoral rionegrino (Argentina) durante el Holoceno medio y tardío. En Arqueología de la Patagonia: Una Mirada desde el Último Confín, editado por M. Salemme, F. Santiago, M. Alvarez, E. Piana, M. Vázquez y E. Mansur, pp. 985-997. Editorial Utopías, Ushuaia.

Favier Dubois, C.M. y F. Borella 2011. Contrastes en la costa del golfo: una aproximación al estudio del uso humano del litoral rionegrino. En Arqueología de Pescadores y Marisqueadores en Nordpatagonia. Descifrando un Registro de más de 6.000 Años, editado por F. Borella y M. Cardillo, pp. 13-42. Editorial Dunken, Buenos Aires.

Favier Dubois, C.M. y F.L. Scartascini 2012. Intensive fishery scenarios on the north Patagonian coast (Río Negro, Argentina) during the mid-Holocene. Quaternary International 256:62-70.

Favier Dubois, C.M. 2013. Geoarqueología en la costa norpatagonica: Contexto geomorfológico cronológico y ambiental del registro litoral. En Geoarqueología, editado por J. Rubin de Rubin y R. Theodoro Da Silva, pp. 69-89. Universidad Pontificia Católica de Goiás, Brasil 
Favier Dubois, C.M. 2019. Human occupation chronologies modeled by geomorphological factors: A case study from the Atlantic Coast of Northern Patagonia (Argentina). En Advances in Coastal Geoarchaeology in Latin America, editado por $\mathrm{H}$. Inda Ferrero y F. García Rodríguez, pp. 1-15. Springer, Chamd.

Fernández-Jalvo, Y. y P. Andrews 2016. Atlas of Taphonomic Identifications. 1001+ Images of Fossil and Recent Mammal Bone Modification. Springer, Nueva York, Londres.

Gelós, E.M., R.A. Schillizzi y J.O. Spagnuolo 1990. Interpretación litoestratigráfica de un tramo de costa al sur de Punta Pórfido, provincia de Río Negro. Revista de la Asociación Geológica Argentina XLV (3-4):397-402.

Goldberg, P. y S.C. Sherwood 2006. Deciphering human prehistory through the geoarcheological study of cave sediments. Evolutionary Anthropology: Issues, News, and Reviews 15 (1):20-36.

Goudie, A.S. 2004. Insolation weathering. En Encyclopedia of Geomorphology, editado por A.S. Goudie, Vol. 1, pp. 566-567. Routledge, Londres.

Groom, K.M., C.D. Allen, M. Mol, T.R. Paradise y K. Hall 2015. Defining tafoni: Re-examining terminological ambiguity for cavernous rock decay phenomena. Progress in Physical Geography 39 (6):775-793.

Gifford-Gonzalez, D.P., D.B. Damrosch, D.R. Damrosch, J. Pryor y R.L. Thunen 1985. The third dimension in site structure: An experiment in trampling and vertical dispersal. American Antiquity 50 (4):803-818.

Huinink, H.P., L. Pel y K. Kopinga 2004. Simulating the growth of tafoni. Earth Surface Processes and Landforms 29:1225-1233.

Lyman, R. 2008. Quantitative Paleozoology. Cambridge Manuals in Archaeology, Cambridge University Press, Cambridge.

Martínez, G.A. 2007. Procesos de formación de sitios en reparos rocosos de Tandilia. Cazadores-Recolectores del Cono Sur. Revista de Arqueología 3:105-127.

Nielsen, A.E. 1991. Trampling the archaeological record: An experimental study. American Antiquity 56 (3):483-503.

Olivier, S.R. (ed.) 1973. Relevamiento Ecológico y Tipificación de las Comunidades del Litoral Marítimo de la Provincia de Río Negro, con Especial Referencia al Establecimiento de áreas de Cultivo para Especies de Interés Comercial. Instituto de Biología
Marina. Asesoría de desarrollo de Río Negro. Consejo Federal de Inversiones. Buenos Aires.

Porras Martín, J., P. Nieto López-Guerrero, C. Álvarez Fernández, A. Fernández Uría y M.V. Gimeno 1985. Calidad y Contaminación de las Aguas Subterráneas en España. Editorial IGME, Madrid.

Retallack, G.J. 1990. Soils of the Past. An Introduction to Paleopedology. Harper Collins Academic, Londres.

Rosato, V.G. 2010. Líquenes como posibles agentes de deterioro de areniscas en las ruinas jesuíticas de San Ignacio Miní (provincia de Misiones, Argentina). Materiales de Construcción 60 (299):145-153.

Scasso, R.A. y C.O. Limarino 1997. Petrología y Diagenesis de Rocas Clásticas. Asociación Argentina de Sedimentología, Buenos Aires.

Schnepfleitner, H., O. Sass, S. Fruhmann, H. Viles y A. Goudie 2015. A multi-method investigation of temperature, moisture and salt dynamics in tafoni (Tafraoute, Morocco). Earth Surface Processes and Landforms 41:473-485.

Skinner, B.J. y S.C. Porter 2000. The Dynamic Earth. An Introduction to Physical Geology (4ta ed). John Wiley \& Sons, Nueva York.

Straus, L.G. 1990. Underground archaeology: Perspectives on caves and rockshelters. En Archaeological Method and Theory 2, editado por M.B. Schiffer, pp. 255-304. University of Arizona Press, Tucson.

Turkington, A.V. 2004. Cavernous weathering. En Encyclopedia of Geomorphology, editado por A.S. Goudie, Vol. 1, pp. 128-130. Routledge, Londres y New York.

Turkington, A.V. y J. Phillips 2004. Cavernous weathering, dynamical instability and self-organization. Earth Surface Processes and Landforms 29 (6):665-675.

Villar, J., A. Virella, V. Saavedra, J. Ruíz y L. De la Torre 1983. Las capas fluidas de la tierra. Interacciones con la superficie sólida. En Geología. $2^{\circ}$ edición, pp. 131-167. Editorial Rueda, Madrid.

Waters, M.R. 1992. Principles of Geoarchaeology: A North American Perspective. University of Arizona Press, Tucson.

Zubimendi, Á. y P. Ambrústolo 2016. Estudio comparativo de abrigos rocosos en la costa norte de Santa Cruz (Patagonia). Comechingonia. Revista de Arqueología 20 (1):253-276. 